\title{
Influence of Annealing Temperature on the Mechanical Properties of Sol-Gel ZnO Films
}

\author{
Kyle J. Burrows
}

Follow this and additional works at: https://researchrepository.wvu.edu/etd

\section{Recommended Citation}

Burrows, Kyle J., "Influence of Annealing Temperature on the Mechanical Properties of Sol-Gel ZnO Films" (2014). Graduate Theses, Dissertations, and Problem Reports. 5286.

https://researchrepository.wvu.edu/etd/5286

This Thesis is protected by copyright and/or related rights. It has been brought to you by the The Research Repository @ WVU with permission from the rights-holder(s). You are free to use this Thesis in any way that is permitted by the copyright and related rights legislation that applies to your use. For other uses you must obtain permission from the rights-holder(s) directly, unless additional rights are indicated by a Creative Commons license in the record and/ or on the work itself. This Thesis has been accepted for inclusion in WVU Graduate Theses, Dissertations, and Problem Reports collection by an authorized administrator of The Research Repository @ WVU. For more information, please contact researchrepository@mail.wvu.edu. 
Influence of Annealing Temperature on the Mechanical Properties of Sol-Gel ZnO Films

$$
\text { Kyle J. Burrows }
$$

Thesis submitted to the

Benjamin M. Statler College of Engineering and Mineral Resources at West Virginia University in partial fulfilment of the requirements

for the degree of

\author{
Master of Science \\ in \\ Mechanical Engineering \\ Konstantinos A. Sierros, Ph.D., Chair. \\ Darran R. Cairns, Ph.D. \\ Stephen N. Kukureka, Ph.D.
}

Department of Mechanical and Aerospace Engineering

Morgantown, West Virginia

2014

Keywords: sol-gel, nanoindentation, tribology, scratch, thin films, coatings

Copyright 2014 Kyle J. Burrows. 


\section{Abstract \\ Influence of Annealing Temperature on the Mechanical Properties of Sol-Gel ZnO Films}

Transparent conducting oxides (TCO's) are widely adopted coatings applied to a wide range of applications including; optoelectronics, touch-screens, smart systems, organic light emitting diodes (OLED's), and solar panel technologies. During both fabrication and service, the mechanical reliability of these coatings, such as wear and scratch resistance, is of great importance. Zinc Oxide ( $\mathrm{ZnO})$ coatings have emerged as a highly desirable, and low cost alternative to the commonly adopted Indium Tin Oxide (ITO) since they offer; wide band gap energy $(3.34 \mathrm{eV})$, high optical transmission, and are both chemically and thermally stable.

In this work, the mechanical properties of sol-gel $\mathrm{ZnO}$ films deposited on soda lime glass substrates via the dip coating method was investigated. The objective of this work is to study the influence of differing annealing temperatures may have on the structural, optical, and mechanical properties of sol-gel $\mathrm{ZnO}$ films. For this purpose; $\mathrm{x}$-ray diffraction, nanoindentation, scratch testing, and tribological techniques were utilized in order to gain an understanding of how the sol-gel $\mathrm{ZnO}$ films properties are affected as annealing temperature is increased. Structural analysis indicated that all films were polycrystalline with a wurtzite structure and displayed an increase in crystallinity as the annealing temperature was increased. Using nanoindentation it was observed that the Hardness and Young's Modulus increased from $1.79 \pm 0.57$ to $2.68 \pm 0.87 \mathrm{GPa}$ and $70.19 \pm 17.89$ to $73.72 \pm 11.84 \mathrm{GPa}$ respectively as a result of increasing annealing temperature. Tribological and scratch testing techniques indicated that the adhesion properties of $\mathrm{ZnO}$ films were also improved as a result of increased annealing temperature. On the other hand, optical transmission had been significantly reduced as a result of increasing grain size and coating thickness at higher annealing temperatures. 
"Can you see the pride in the Panther?

As he grows in splendour and grace,

toppling obstacles placed in the way

of the progression of his race."

T. Shakur 


\section{Acknowledgements}

I would like to express my thanks to every person that has helped me along the way during this investigation.

I would like to express my thanks to Dr. Darran Cairns for giving me the opportunity to continue my research interests overseas here in America.

My committee chair, Dr. Konstantinos Sierros for his help, guidance, and support throughout the entire life cycle of this investigation.

Dr. Stephen Kukureka for his continued support, and guidance long after my time at The University of Birmingham had come to an end.

My fellow colleagues: Andrew Hoover, Derrick Banerjee, Jacob Cordonier, Maria Arango, and Deji Abidakun; who have all made invaluable contributions to my time here.

I would like to thank Anton Paar USA for providing instrumentation to be used within this study, without their help, this investigation could not have been possible.

Finally, I would like to thank my family for their constant wealth of love and support, and most importantly, my mother for all that she has done for me. 


\section{Table of Contents}

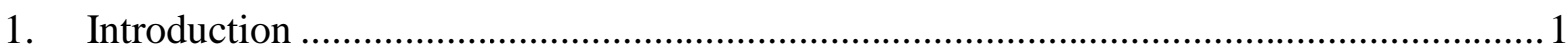

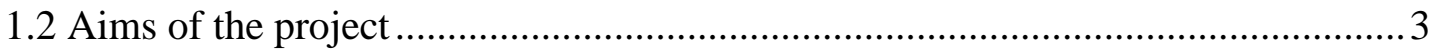

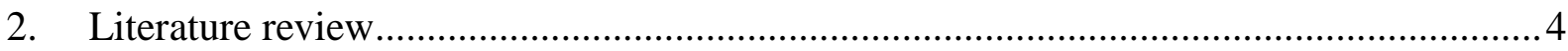

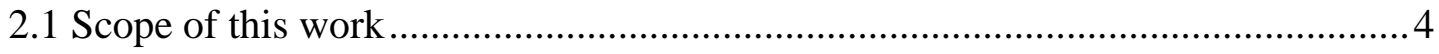

2.2. $\mathrm{ZnO}$ as a replacement for Indium Tin Oxide …..............................................

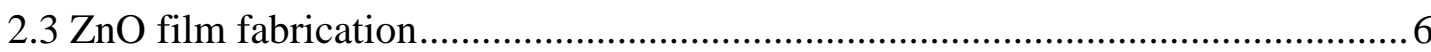

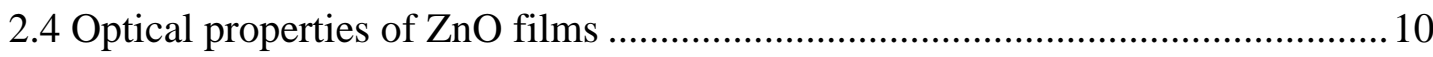

2.5 Mechanical properties of $\mathrm{ZnO}$ films …...................................................... 11

2.6 Methods for material microstructure characterization .................................... 12

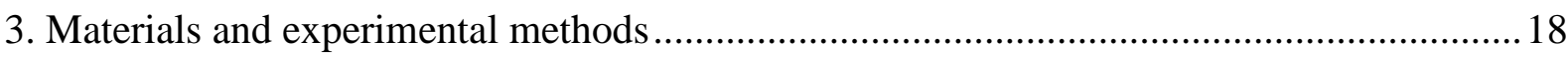

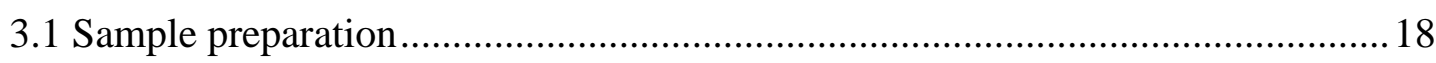

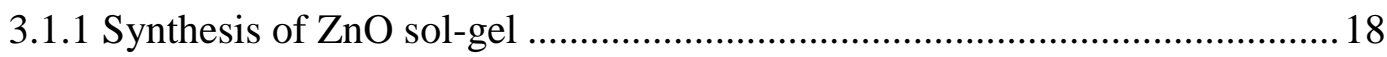

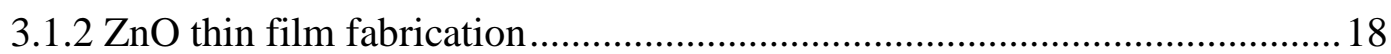

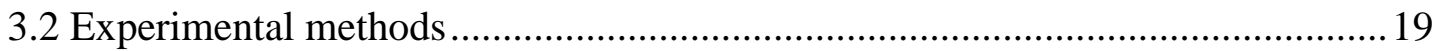

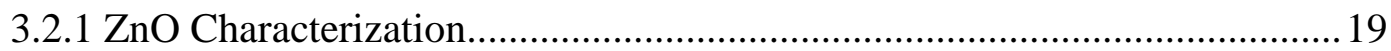

3.2.2 Film Thickness Measurement ................................................................ 19

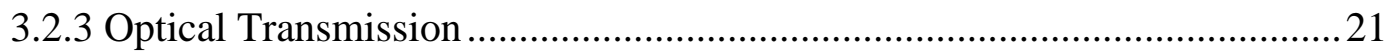

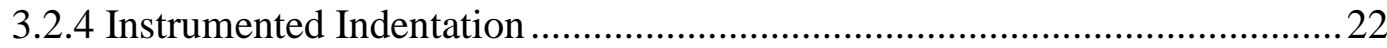

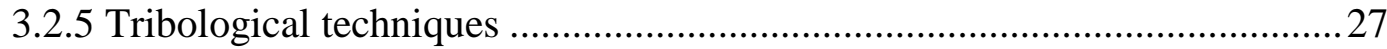

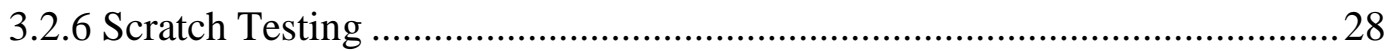




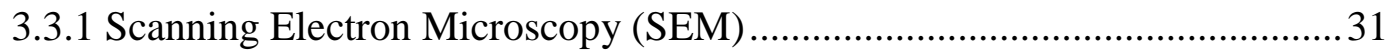

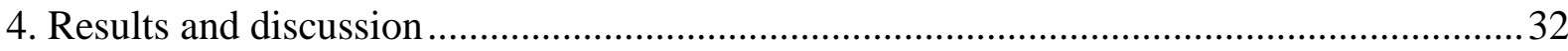

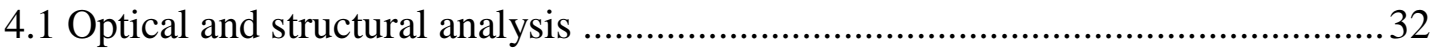

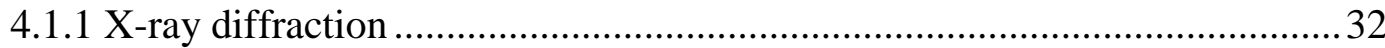

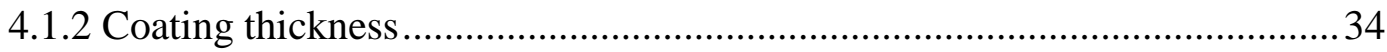

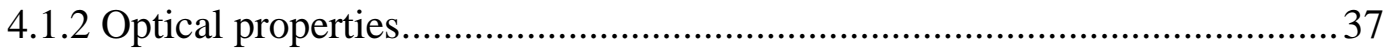

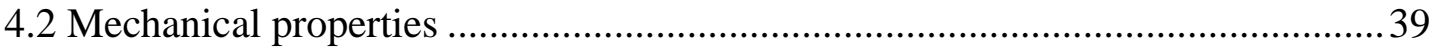

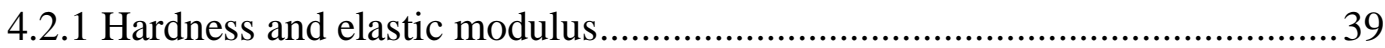

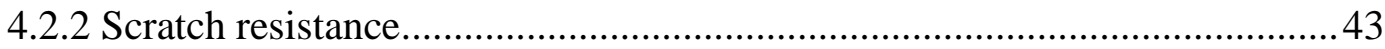

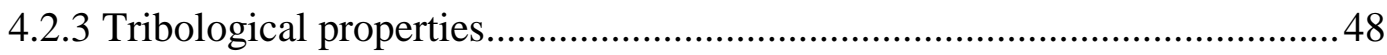

4.3 Surface analysis $4.3 .1 \mathrm{ZnO}$ surface investigation ...........................................51

4.3.2 Ex-situ SEM investigation after mechanical characterization ......................53

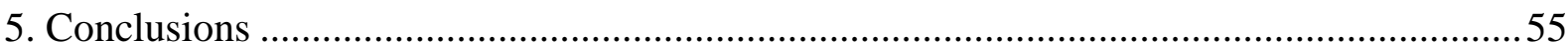

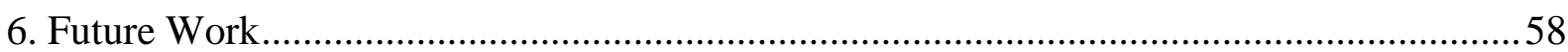

7. References 


\section{Introduction}

Throughout the past few decades, much research has been conducted on the production and application of energy harvesting systems and green energy technologies. Technologies such as solar cells have received a considerable amount of attention from researchers due to both the ongoing concern of global warming, and the depletion of Earth's natural resources. In recent years, an explosive area of research on transparent conducting oxides (TCO's) is noted. TCO's are utilized as conducting anode materials for use in solar cell technologies, and have also been widely adopted in a range of other applications such as; display technologies, piezoelectric devises, photocatalysts and gas sensing technologies (Kumar et al., 2013, Sierros et al., 2011, Cheng et al., 2010, Kim, 2007 , Shinde et al., 2007).

In this endeavour, environmentally safe conducting oxide materials such as titanium dioxide $\left(\mathrm{TiO}_{2}\right)$, tin dioxide $\left(\mathrm{SnO}_{2}\right)$, and zinc oxide $(\mathrm{ZnO})$ can be integrated into solar cell technologies as they have the ability to use sunlight to activate their photocatalytic reactions (Rajeshwar et al., 2008). In order for conducting oxides like these to be efficiently used in such technologies, the coatings must be both functional and mechanically robust. Therefore, the mechanical properties of such conducting oxide materials must exhibit; desirable strength, hardness and adhesive properties whilst maintaining an efficient level of optical transmittance and electrical conductivity.

However, in order to meet the requirements needed for these devices to work in service, there often tends to be a compromise between the mechanical properties, and other requirements and/or functional properties such as; thermal stability, coating thickness, optical transmittance and substrate dependence. For example, relatively hard coating materials normally require undesirable deposition techniques and often are not optically transparent. In 
order to progress this research further, design and optimization of conducting oxide materials to provide high strength, hardness, adhesion, and wear resistance properties without diluting other essential characteristics is essential. For example, TCO's such as $\mathrm{ZnO}$ are often doped with a material such as; aluminium, boron, gallium, neodymium, and copper in an attempt to increase the electrical properties of fabricated $\mathrm{ZnO}$ films as a transparent anodic material. However, these elemental additions, and the weight percentage at which they are added will result in a variation of the optical and mechanical properties of the resulting TCO film.

For this study, spectroscopy and mechanical characterization techniques have been adopted in order to quantify the optical and mechanical properties of un-doped sol-gel $\mathrm{ZnO}$ films, and to investigate how the annealing temperature during fabrication may influence such properties. Since research thus far has focussed on aspects of optical and mechanical properties individually, and has mainly focused on doped $\mathrm{ZnO}$ materials, this investigation will allow for a broader and relatable understanding of how the annealing temperature influences these essential properties of un-doped $\mathrm{ZnO}$ films 


\subsection{Aims of the project}

1) To investigate how the optical properties of $\mathrm{ZnO}$ thin films are affected as annealing temperature is increased; as these systems can be deposited at a number of pre-heating and annealing temperatures during the manufacturing process. The optical reliability of these systems is vital during service; therefore any detrimental effects to these optical properties need to be understood.

2) To investigate how the tribological properties of these thin film systems can be affected as a result of varying annealing temperatures. When these systems are fabricated and when in service conditions there is a possibility that they may come into contact with a third surface. Furthermore, the designed function of the device may require it to operate in a sliding motion such as micro-electromechanical systems. Therefore, a detailed understanding of the tribological nature of these systems is required.

3) To analyse the mechanical behaviour of $\mathrm{ZnO}$ films as a function of increasing annealing temperature. During both service, and in the manufacturing process, these films can be exposed to a range of external stresses. It is therefore important to investigate the mechanical properties of such TCO films. 


\section{Literature review}

\subsection{Scope of this work}

The main objective of this work is to gain an understanding of how annealing temperature may influence the surface mechanical and tribological properties of $\mathrm{ZnO}$ thin films fabricated via the Sol-Gel process. It is imperative that one has a broad knowledge of the work that has been conducted previously within this research topic area, in order to progress the topic further. The following chapter aims to review the relevant work from this field of study, in order to gain a full understanding of how the annealing temperature may affect $\mathrm{ZnO}$ thin film properties. 


\section{2. $\mathrm{ZnO}$ as a replacement for Indium Tin Oxide}

Indium Tin Oxide (typically 90 wt\% In2O3, 10 wt\% SnO2 (Hartnagel, 1995)), commonly abbreviated as ITO, has been a heavily researched system and is widely adopted as one of the most popular materials for use as a transparent conducting oxide (TCO). Several favourable properties of ITO have been the source of its popularity such as; high optical transmittance (> $90 \%)$ due to it being a wide band gap material (> $3 \mathrm{eV})$, and low electrical resistivity $\left(2 \times 10^{-4}\right.$ $\Omega / \mathrm{cm}$ (Choi et al., 2008)). However, these favourable properties can be heavily influenced by defects such as surface roughness, and an increase in $\mathrm{O}_{2}$ vacancies within the crystal lattice. As a result of these defects, a reduction of the energy bang gap can be noted, which in turn results in a decrease of carrier mobility and therefore, optical transmission (Kim, 2007 ). One of ITO's main limitations however, is the scarcity of indium. Due to this rarity, indium can be a very expensive material, and its price can further fluctuate considerably as time advances. Therefore, much research has been devoted into finding cheaper alternative materials that can replicate the highly desirable properties of indium tin oxide.

One such material is that of Zinc Oxide $(\mathrm{ZnO})$. Much like ITO, $\mathrm{ZnO}$ has a wide band gap $(3.34 \mathrm{eV})$ (Minami, 2005), high optical transmission, is non toxic, is both chemically and thermally stable, exhibits desirable electron mobility, and is environmentally safe (Kim et al., 2000). Furthermore, $\mathrm{ZnO}$ is suited for environmental applications since it has been shown to degrade dirt and inhibit the growth of microorganisms (Padmavathy and Vijayaraghavan, 2008). Moreover, the most desirable property of $\mathrm{ZnO}$ is the price. Due to the surplus of Zinc available compared to Indium (132 and $0.1 \mathrm{ppm}$ respectively as per a study conducted by (Ellmer, 2001)), ZnO has been researched as a highly desirable, and cheaper alternative to ITO. 


\subsection{ZnO film fabrication}

Numerous deposition methods have been previously used and investigated for $\mathrm{ZnO}$ film synthesis, including; pulsed laser deposition (PLD), metal-organic chemical vapour deposition, sputtering, spray pyrolysis (Paraguay D et al., 1999), and the sol-gel technique to name but a few (Lennon et al., 2009, Miccoli et al., 2014, Sierros et al., 2010). Paraguary D et al., (1999) investigated the growth and structure of $\mathrm{ZnO}$ films onto glass substrates using a spray pyrolysis system. Spray pyrolysis, a form of chemical vapour deposition (CVD), is a commonly used technique that has been vastly utilised within the glass, and solar cell industry to deposit coating materials onto substrates to be used as conducting electrodes (Thangaraju and Kaliannan, 2000). Their results suggested that by using a spray nozzle of a reduced diameter and an oscillating heated sample stage they were able to increase the velocity of the aqueous zinc acetate solution droplets onto the glass substrate in order to facilitate film uniformity. Furthermore, by controlling the deposition time they were able to control the thickness of the fabricated $\mathrm{ZnO}$ films where an increase in deposition time resulted in a thicker film. A preferred critical temperature of $\sim 600$ Kelvin $\left(326^{\circ} \mathrm{C}\right)$ was found to fabricate a $170 \mathrm{~nm} \mathrm{ZnO}$ film with high optical transmission (85\%), and preferential growth along the crystallographic c-axis perpendicular to the substrate. Films heated below $326^{\circ} \mathrm{C}$ resulted in a highly porous microstructure.

When comparing spray pyrolysis to other deposition techniques such as sputtering or evaporation, several differences can be observed; the kinetic energy of the reactants within the spray system is very low in comparison $\left(\sim 10^{-1} \mathrm{eV}\right)$, higher atmospheric ambient gas pressure is needed, a much lower deposition rate can be observed $(\sim 1 \mathrm{~nm} / \mathrm{s})$ resulting in longer fabrication times and higher costs, and the maximum film thickness obtained is $\sim 300 \mathrm{~nm}$ 
(Paraguay D et al., 1999). This often results in films exhibiting less than desired mechanical, and microstructural properties due to process defects.

The PLD technique however, has been shown to produce high quality films, with highly desirable properties such as; low electrical resistance, low surface roughness, deposition at low temperatures (below $100^{\circ} \mathrm{C}$ ) and high optical transmission (85-90\%). This deposition technique works by using a high-powered pulsed laser which is focused upon the target material within a vacuum. Once the laser energy density reaches a preset threshold, a laser induced plasma plume is produced, and material from the target is vaporised and deposited onto the substrate material as a result (Kim et al., 2001). It has been previously stated that depositing transparent conducting oxides at lower temperatures can result in less than desirable properties such as poor optical transmission and high electrical resistance (Kim et al., 2001). The capability to maintain desirable mechanical and microstructural properties at low deposition temperatures enables a wider range of materials to be used as the substrate material, such as polymers. Polymer substrates require deposition temperatures of below $200^{\circ} \mathrm{C}$, and are capable of being the platform for a range of flexible device applications such as flexible displays and flexible solar cells. Kim et al., (2001) deposited indium tin oxide (ITO) on to polymer substrates at temperatures below $100^{\circ} \mathrm{C}$ and were able to measure electrical resistance as low as $4 \times 10^{-4} \Omega / \mathrm{cm}$ and an average optical transmission of $90 \%$ by using the PLD technique.

This deposition technique was further developed by Chung et al., (2004) where numerous TCO's were deposited on polymer substrates at room temperature. Deposition was then followed by an annealing process using a $\mathrm{XeCl}$ excimer laser, which resulted in a significant increase in the optical and electrical properties of the resultant films when compared to other room temperature deposition methods (Chung et al., 2004). Although the 
PLD process can achieve highly desired properties for coated thin films such as; low surface roughness at low deposition temperatures, the limited area of the ablated plume results is a maximal sample size of $\sim 1 \mathrm{~cm}$. Due to the significantly small sample size, and vacuum conditions needed, this deposition method eliminates the possibility of mass production. Other TCO fabrication techniques such as ion beam assisted deposition and reactive DCMagnetron sputtering have also been reported to yield films with desirable properties (YoungSoon Kim and Shin, 2003). Although the PLD process can achieve highly desired properties for coated thin films such as a low surface roughness at low deposition temperatures, the limited area of the ablated plume results is a maximal sample size of $\sim 1 \mathrm{~cm}$. Due to the significantly small sample size, and vacuum conditions needed, this deposition method eliminates the possibility of mass production.

The sol-gel process however possesses distinct advantages over other deposition methods due to its excellent compositional control, homogeneity down to the molecular level, no need for vacuum conditions, simplicity, deposition at room temperature, and most importantly low cost (Liu et al., 2014). The sol-gel deposition technique allows powderless processing of thin oxide films on numerous substrate materials from a solution, where the synthesis involves wet chemistry reactions based on transformation of molecular precursors into an oxide network by hydrolysis and condensation reactions (Znaidi, 2010). In order to fabricate films from the sol-gel deposition process, one must firstly prepare the pre-cursor solution; the sol can then be prepared for deposition onto the substrate material by the chosen technique (dip or spin coating), and then finally the films are heat-treated. An outline of the sol-gel deposition process can be seen in Figure 1. In particular, a molecular precursor in a homogenous solution goes through a number of transformations including; hydrolysis, polymerization, condensation by dehydration, and finally nucleation and growth (Pierre, 
1998). Many zinc precursors have been utilised in the past, such as nitrates, chlorides and alkoxides. However, the most commonly used precursor is zinc acetate due to its counter anion and to the fact that it is readily dissolvable in solvents such as Isopropanol (Znaidi, 2010). Monoethanolamine (MEA) is often included in the solvent precursor solution in order to act as a base and complexing agent. Previous research has shown that when zinc acetate is diluted in Isopropanol with added MEA, and it is aged at $60-100^{\circ} \mathrm{C}$, formation of translucent sols can be achieved, where as when nitrates were used as the precursor material no sols could be reproducibly obtained (Znaidi et al., 2003).

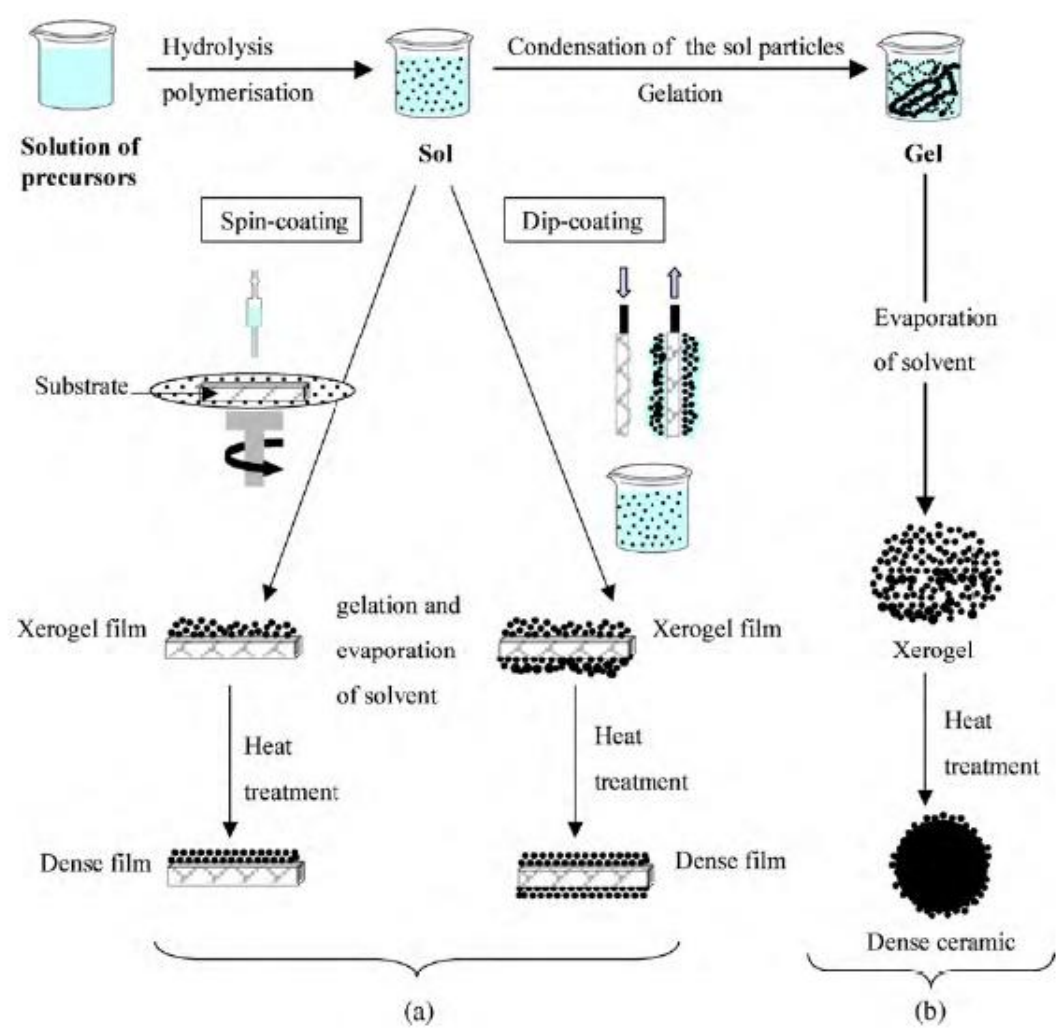

Figure 1 Outline of the sol-gel deposition method for films from; (a) a colloidal sol, and (b) a powder from a colloidal sol transformed into a gel (image courtesy of (Znaidi, 2010)) 
Thongsuriwong et al., (2013) deposited $\mathrm{ZnO}$ films of varying zinc acetate concentrations on soda lime glass substrates using the sol-gel dip-coating method. Their research noted that as the zinc acetate concentration of the sol increase from $0.1 \mathrm{M}$ to $0.3 \mathrm{M}$, the resulting film thickness also increased from $218 \mathrm{~nm}$ to $437 \mathrm{~nm}$ respectively. Furthermore, their work also showed that $\mathrm{ZnO}$ films with lower zinc acetate concentrations $(0.1 \mathrm{M})$ displayed an increase in surface roughness of 4.956 Rrms compared to its $0.3 \mathrm{M}$ counterpart $(2.538 \mathrm{Rrms})$ (Thongsuriwong et al., 2013). Additionally, research has found that by altering the withdrawal speed, and number of times the sample is dipped in the sol solution will result in a change in the film thickness. A faster withdrawal speed, and an increase in the number of dips both contribute to an increase of the film thickness (Li et al., 2012, Malek et al., 2014) Furthermore, it has been shown that by increasing the withdrawal speed from $40 \mathrm{~mm} / \mathrm{min}$ to $50 \mathrm{~mm} / \mathrm{min}$ during dip coating may result in a decrease in the XRD peak intensity relating to the (002) plane.

\subsection{Optical properties of $\mathrm{ZnO}$ films}

Optical clarity in the visible range is one of the most important properties for optoelectronic technologies, and furthermore high optical transmittance has been shown to directly correlate to an increase in efficiency and performance of solar panels (Schubert et al., 2014). With this in mind it is imperative that one understands how the $\mathrm{ZnO}$ films optical transmittance may be influenced by the processing parameters. In particular, Liu et al., (2014) investigated such properties of aluminium doped $\mathrm{ZnO}$ films that had been processed using the sol-gel method with respect to differing heat treatments. Results showed that post-heat treatment at $600^{\circ} \mathrm{C}$ for 1 hour, increased the AZO films optical transmission to $86.7 \%$ in comparison to just $82.9 \%$ when the films were exposed to a pre-heat treatment phase of $450^{\circ} \mathrm{C}$. This increase in optical transmission was stated to be attributed to the reduction of light scattering within the 
film as a result of an increase in crystal structure density after post-heat treatment (Liu et al., 2014). Malek et al., (2014) also indicated that as sol-gel dip-coating deposition speeds surpassed $10 \mathrm{~mm} / \mathrm{min}, \mathrm{ZnO}$ films exhibited a decrease in optical transmission due to the formation of larger particles and an increase in film thickness.

\subsection{Mechanical properties of $\mathrm{ZnO}$ films}

Due to the wide range of applications $\mathrm{ZnO}$ films can be used for, and the robust nature of which many of these applications go through during both manufacturing and service, it is imperative that the mechanical properties of such films are understood.

Kiriakidis et al., (2014) fabricated $1 \mu \mathrm{m} \mathrm{ZnO}$ films on soda lime glass substrates utilising the sol-gel dip-coating method. The hardness, elastic modulus and tribological properties were investigated using a Nanoindentation tester and a lab-built wear tester. During indentation testing, the indentation depth was kept below $10 \%(<100 \mathrm{~nm})$ of the total film thickness $(1 \mu \mathrm{m})$ to avoid any undesirable effect of the underlying substrate, and a maximum load of $05 \mathrm{mN}$ was reached. The hardness and modulus values were found to be $3.86 \pm 0.47 \mathrm{GPa}$ and $81.31 \pm 9.97 \mathrm{GPa}$ respectively. In addition to indentation testing, the tribological properties were also investigated using an in-house rolling tester with an applied rolling frequency. Results showed that as the rolling test surpassed 200 cycles, both microcrack and film delamination could be observed. Further increasing the number of wear cycles past this point caused these failure mechanisms to become more pronounced, indicating that surface fatigue and surface debris build up play a significant role in the wear failure mechanisms of $\mathrm{ZnO}$ films (Kiriakidis et al., 2014).

Work by Banerjee (2012) showed the importance of ensuring that indentation depth remained below $10 \%$ of the total coating thickness. During this investigation, mesoporous silica films, with $0.5-10 \mathrm{wt} \%$ of added silica particles were analysed. The influence of 
substrate effect was clearly seen within this investigation as indentation of a $2 \%$ silica doped $\mathrm{ZnO}$ film showed that at an indentation depth of $10 \%$ of the film thickness resulted in a hardness of $3.1 \mathrm{GPa}$, compared to a hardness of $4.8 \mathrm{GPa}$ seen at an indentation depth of $40 \%$ (Banerjee, 2012).

\subsection{Methods for material microstructure characterization}

$\mathrm{X}$-ray Diffraction, commonly abbreviated as XRD has been widely adopted within research as a pivotal technique in order to characterize the crystallinity and crystalline orientation of $\mathrm{ZnO}$ thin films. Malek et al., (2014) investigated $\mathrm{ZnO}$ thin film crystalline orientation by differing deposition speeds whilst fabricating $\mathrm{ZnO}$ thin films via a sol gel process. Altering the deposition speed during sol gel fabrication can affect both the surface morphology and the film thickness. The XRD patterns for films deposited at $50 \mathrm{~mm} / \mathrm{min}$ to $10 \mathrm{~mm} / \mathrm{min}$ can be seen in Figure 2. Brinker and Scherer (1990) stated that a lower deposition speed would result in a thinner film post fabrication as the slower deposition speed facilitated solvent evaporation from the film (Brinker and Scherer, 1990). Malek et al., (2014) found via x-ray diffraction that all their fabricated $\mathrm{ZnO}$ thin films exhibited strong orientation towards the (002) plane diffraction peak, the strongest of which was at a deposition speed of $40 \mathrm{~mm} / \mathrm{min}$ at $2 \theta=34.56^{\circ}$ indicating a single phase $\mathrm{ZnO}$ with a hexagonal wurtzite structure (Malek et al., 2014). Their results also found that as they decreased the deposition speed, a decrease within the (002) plane orientation XRD peak could also be observed. Indicating $\mathrm{ZnO}$ films do not grow effectively at lower deposition speeds. This could be due to an insufficient amount of $\mathrm{Zn}^{2+}$ ions resulting in slower growth when compared to films fabricated at higher deposition speeds (Malek et al., 2014). Kumar et al. (2013) also used XRD in order to characterize the crystalline orientation of their Aluminium doped $\mathrm{ZnO}$ nanorods prepared via the sol gel 
method. The XRD patterns confirmed that a single $\mathrm{ZnO}$ nanorod was successfully grown along the (002) plane direction (Kumar et al., 2013).

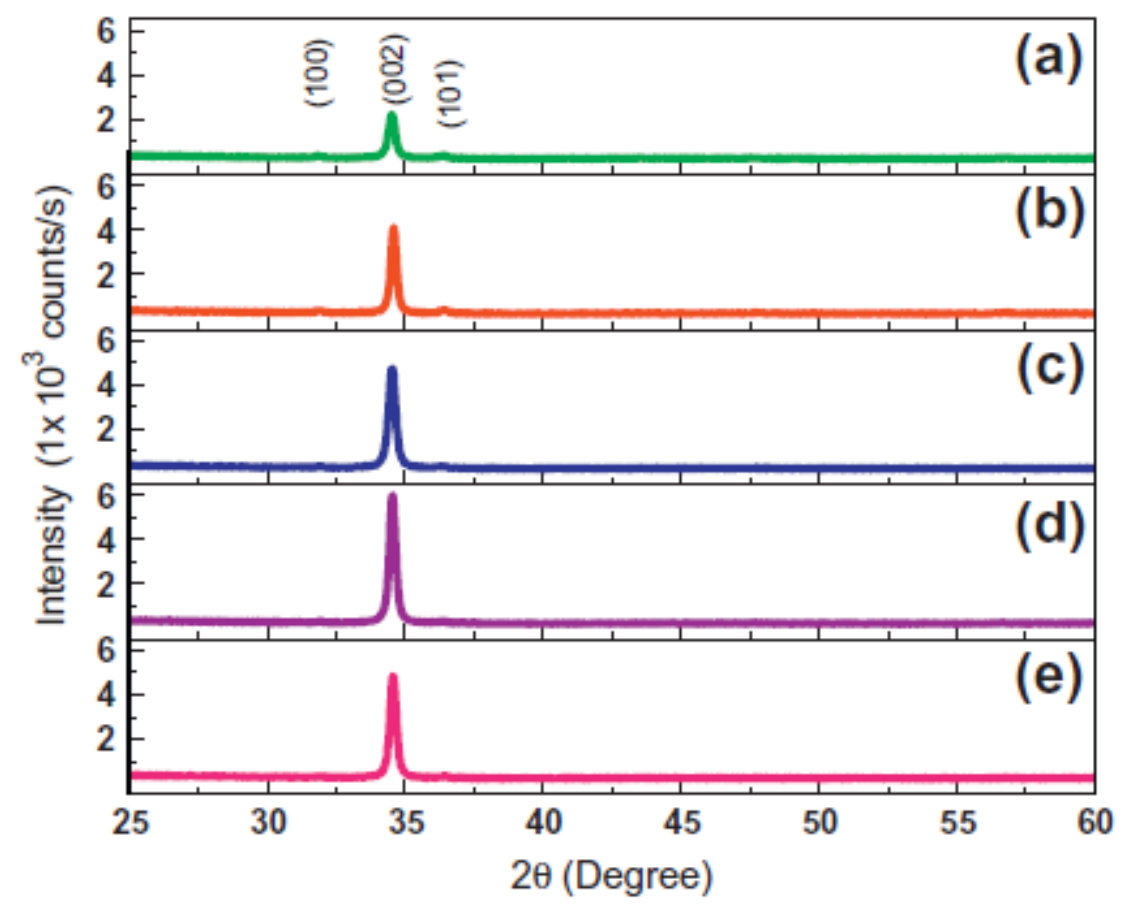

Figure 2 XRD patterns of $\mathrm{ZnO}$ films deposited at various deposition speeds; (a) $10 \mathrm{~mm} / \mathrm{min}$, (b) $20 \mathrm{~mm} / \mathrm{min}$, (c) 30mm/min), (d) 40mm/min, and (e) 50mm/min. (image courtesy of (Malek et al., 2014))

The Scanning Electron Microscope, commonly referred to as SEM, is a microscopy technique that scans a sample with an electron beam under vacuum conditions of around $10^{-4}$ to $10^{-10}$ Torr in order to generate a magnified image of the sample (Swapp, 2013). The SEM belongs to the electron microscope family, which also includes Transmission Electron Microscopy (TEM) and Scanning Transmission Electron Microscopy (STEM) that exhibit a greater degree of magnification and resolution than what is achievable with optical microscopes.

Liu et al. (2014) also used SEM to study the surface morphology of Aluminium doped Zinc Oxide thin films. The SEM images were able to show differences in surface morphology of the $\mathrm{Al}$-doped $\mathrm{ZnO}$ thin films that were exposed to differing heat treatment conditions, and it was observed that an increase in the annealing temperature and time 
resulted in a thin film with improved structural homogeneity and a greater degree of crystallinity (Liu et al., 2014). Kumar et al., (2013) also used SEM imaging in order to characterize the height, and size distribution of the fabricated $\mathrm{ZnO}$ nanorods. The results indicated that the diameter of the nanorods varied from $50 \mathrm{~nm}$ to $150 \mathrm{~nm}$, with an average length ranging from 400nm to 600nm, which can be seen in Figure 3.

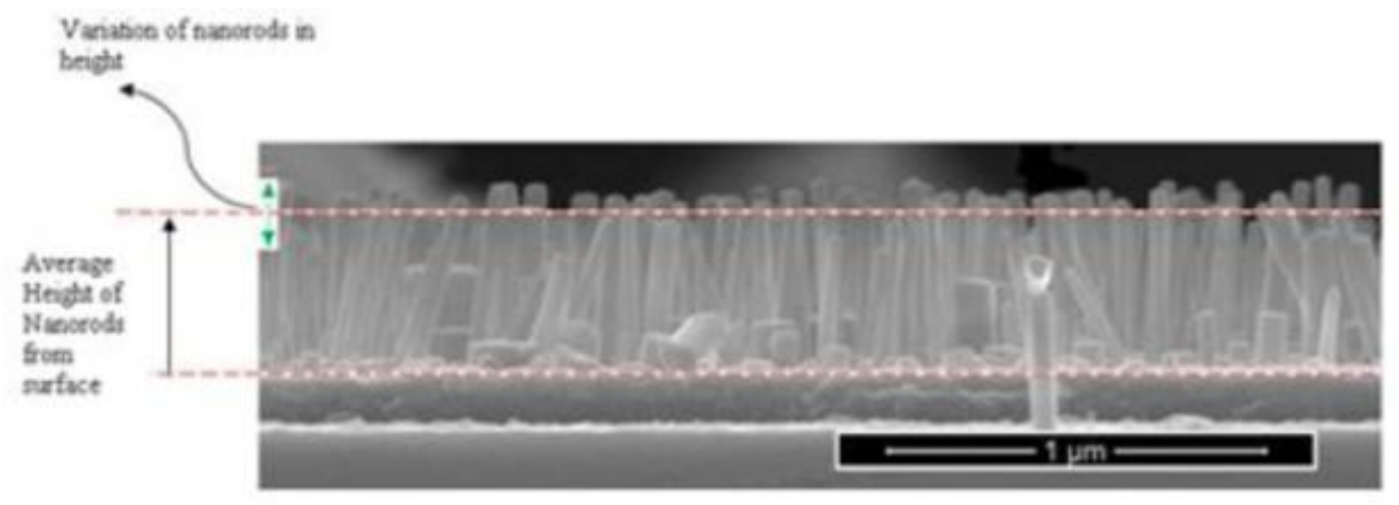

Figure 3 Cross-sectional SEM image of ZnO nanorods. (image courtesy of (Kumar et al., 2013))

As previously discussed, the structural characterization of $\mathrm{ZnO}$ thin films is vital in the understanding of how to optimize their application performance and efficiency. Where the SEM can be useful in the characterization of the surface topography, texture, and chemical composition of $\mathrm{ZnO}$ thin films, Transmission Electron Microscopy (TEM) is able to give detailed structural information down to the atomic level. The TEM is able to provide such detailed characterization via direct lattice imaging and electron diffraction.

Ko, Him and $\mathrm{Yu}$ (2012) investigated the structural and optical properties of vertically aligned $\mathrm{ZnO}$ nanorod arrays grown on flexible ITO coated PET substrates. To understand the effect of adding a $\mathrm{ZnO}$ seed layer on the growth property, the $\mathrm{ZnO}$ nanorods were deposited with and without a seed layer. Morphology and structural analysis was performed using a FE- 
SEM and TEM, whilst the growth and crystalline properties were observed via XRD spectra's (Ko et al., 2012). The FE-SEM images were used to investigate the effect of applied cathodic voltage on the morphology and density of the $\mathrm{ZnO}$ nanorods within the samples. Analysis of the high resolution TEM contrast images was able to indicate that the lattice fringes of a detached $\mathrm{ZnO}$ nanorod were ordered perpendicular to the growth direction.

Hamrouni et al., (2013) utilized the use of TEM to characterize the microstructure of their $\mathrm{ZnO}-\mathrm{SnO}_{2}$ nanocomposites that were fabricated via the sol gel route. Whilst characterization via XRD and SEM allows the material grain size to be calculated, it can be very difficult and is often misinterpreted due to the grains small scale. The TEM was used to calculate the size of a single nanoparticle, whereas the SEM images were only able to show clusters of nanoparticles. The TEM images were able to show that the nanoparticles ranged from $30-80 \mathrm{~nm}$ in size, and that each nanoparticle was attached to several other nanoparticles. A comparison between a TEM image and an SEM image displaying the characterization of the $\mathrm{ZnO}$ nanoparticles can be seen in Figure 4. 

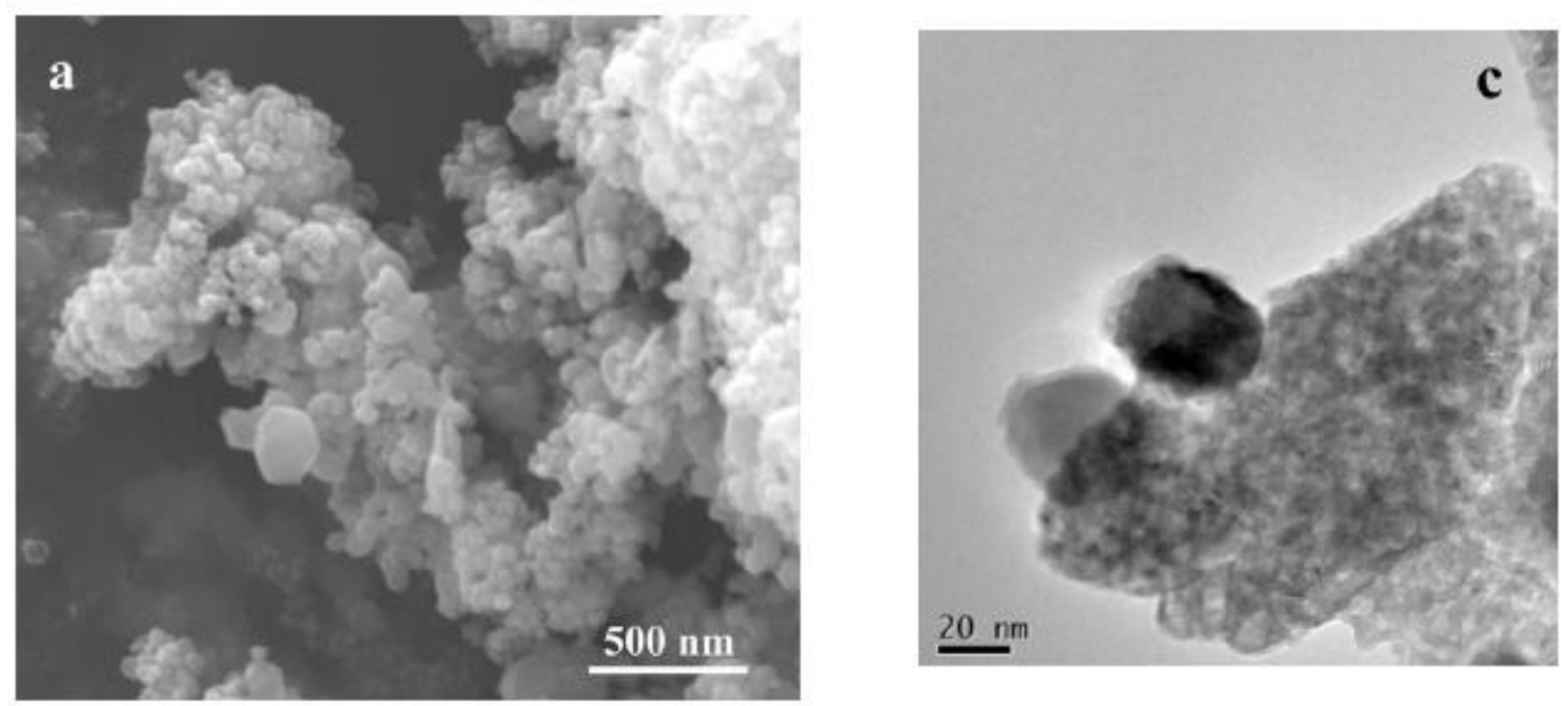

Figure 4 Comparison between SEM and TEM imaging; (a) SEM image of ZnO cluster particles, (c) TEM image of individual ZnSn nanoparticles (image courtesy of Hamrouni et al.,(2014)(Hamrouni et al., 2014))

Previously to this work researchers had already used TEM to characterize the grain size of $\mathrm{ZnO}$ thin films. Gong et al., (2006) prepared $\mathrm{Cu}$-doped $\mathrm{ZnO}$ thin films on glass substrates in order to analyze the films carbon monoxide (CO) gas sensing capabilities at operating temperatures ranging from 150 to $400^{\circ} \mathrm{C}$ (Gong et al., 2006). The $\mathrm{ZnO}$ based sensor is able to detect $\mathrm{CO}$ by analyzing the changes in $\mathrm{ZnO}$ electrical conductivity upon exposure to the target gas (Yoon and Choi, 1997). For $\mathrm{ZnO}$ film to be effective as a gas sensor, it is imperative that the grain sizes of the fabricated thin film are on the nano-scale. While the SEM was able to characterize the $\mathrm{Cu}$-doped $\mathrm{ZnO}$ film thickness to be $\sim 260 \mathrm{~nm}$, the TEM was able to measure the crystalline grains to be $\sim 5 \mathrm{~nm}$, as well as displaying nano-scale amorphous regions. Additionally, Wang et al., (2005) synthesized $\mathrm{ZnO}$ nanowires via a physical vapour deposition process, utilizing c-oriented $\mathrm{ZnO}$ thin films as the substrate material. Within this project, SEM was used in order to determine the morphology of the of the $\mathrm{ZnO}$ thin films, where the diameters of the $\mathrm{ZnO}$ nanowires were found to be between $60 \mathrm{~nm}$ to $120 \mathrm{~nm}$ with a 
typical length of $4 \mu \mathrm{m}$. Moreover, high resolution transmission electron microscopy (HRTEM) was utilized to further illuminate the detailed structure of a single synthesized $\mathrm{ZnO}$ nanowire. Via the use of the HRTEM, Wang et al., (2005) was able to display the fringes of $\mathrm{ZnO}$ (001) planes with an interplanar spacing of $\sim 0.52 \mathrm{~nm}$. This was able to confirm that the $\mathrm{ZnO}$ nanowire is crystalline and grows along the [001] direction (Wang L., 2005 ). Although the TEM is highly advantageous, its capabilities exceeds the requirements of this project, where the XRD and SEM are readily available, highly capable, and advantageous techniques for the micro-structural characterization of $\mathrm{ZnO}$ thin films. 


\section{Materials and experimental methods}

\subsection{Sample preparation}

\subsubsection{Synthesis of $\mathrm{ZnO}$ sol-gel}

The $\mathrm{ZnO}$ thin film coatings were fabricated using the sol-gel dip coating method, following the process outlined by (Kiriakidis et al., 2014). Zinc acetate dihydrate $\left(\mathrm{Zn}\left(\mathrm{CH}_{3} \mathrm{OO}\right)_{2} \cdot 2 \mathrm{H}_{2} \mathrm{O}\right)$ was dissolved in a solution of 2-Propanol (IPA) $\left(\mathrm{C}_{3} \mathrm{H}_{8} \mathrm{O}\right)$, and Ethanolamine (MEA), $\left(\mathrm{HOCH}_{2} \mathrm{CH}_{2} \mathrm{NH}_{2}\right)$ at room temperature. To coincide with the procedure outlined by (Kiriakidis et al., 2014), the molar ratio of MEA to zinc acetate was held at a 1:1 ratio. However, the resulting sol concentrations were equal to $0.5 \mathrm{~mol} \mathrm{~L}^{-1}$ and $0.75 \mathrm{~mol} \mathrm{~L}^{-1}$ as

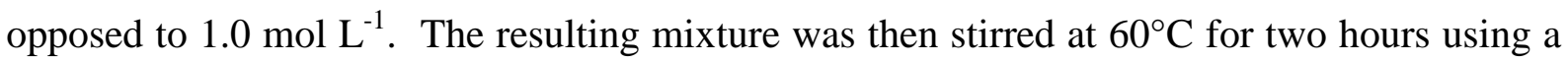
magnetic stirring hotplate (Fisher Scientific ${ }^{\mathrm{TM}}$ Isotemp $^{\mathrm{TM}}$ ) to yield a clear homogenous solution. Upon completion of stirring, the solution was syringe filted using a $0.45 \mu \mathrm{m}$ filter (Fisherbrand) and the resulting sol-gel was left to rest for 24 hours.

\subsection{2 $\mathrm{ZnO}$ thin film fabrication}

Once the $\mathrm{ZnO}$ sol-gel had rested for 24 hours, gel films were deposited on soda-lime glass slide substrates via dip coating using a KSV Dip Coater (KSV Instruments), with a withdrawal rate of $50 \mathrm{~mm} / \mathrm{min}$. Prior to gel coating, all soda-lime glass substrates were cleaned in distilled water and IPA solution in a sonicating water bath (Branson 2510) and then they were rinsed with distilled water and left to dry in ambient conditions. The soda-lime glass substrates were dipped for a total of six times. After each individual dip the samples were pre-heated at a temperature of $250^{\circ} \mathrm{C}$ for 10 minutes in a Lab-Line L-C oven. Once the total number dips had been reached, and all samples had been sufficiently pre-heated, they were then placed in a KSL1100X furnace (MTI Corporation) at 500, 550, and $600^{\circ} \mathrm{C}$ and 
$500^{\circ} \mathrm{C}$ and $600^{\circ} \mathrm{C}$ for 1 hour for 0.5 and $0.75 \mathrm{~mol} \mathrm{~L}^{-1}$ films respectively. A total of $25 \mathrm{ZnO}$ film samples were fabricated for investigation, 5 samples per annealing temperature, for each designated concentration in order to ensure reproducible and reliable data.

\subsection{Experimental methods}

\subsubsection{ZnO Characterization}

The crystal structure of the fabricated $\mathrm{ZnO}$ films was investigated using X-ray Diffraction (XRD). XRD was performed using a Bruker D8 Discover with $\mathrm{Cu} \mathrm{K} \alpha$ radiation and a $2 \theta$ scan from $30^{\circ}$ to $80^{\circ}$ at $0.05^{\circ}$ increments. Total XRD analysis time for each sample was set to 2.7 hours, with a 9 s per step count, and the generator was set to $40 \mathrm{KV}$ and $40 \mathrm{~mA}$.

\subsubsection{Film Thickness Measurement}

The Anton Paar CaloTest was used in order to determine the $\mathrm{ZnO}$ film thicknesses that were fabricated on silica glass substrates. The CaloTest system uses a stainless steel ball of a known diameter $(20 \mathrm{~mm})$ that is pressed into the sample surface as it rotates on a drive shaft at a controlled speed $(300 \mathrm{rpm})$. The position of the stainless steel ball relative to the sample was kept constant and a pre-determined contact angle of $55^{\circ}$ was used. Super-fine water based abrasive diamond slurry, with a particle size of $<2 \mu \mathrm{m}$, was added as the stainless steel ball made contact with the sample in order to abrade into both the $\mathrm{ZnO}$ thin film coating and the silica glass substrate itself. A schematic diagram of the sample setup can be seen in Figure 5. The test was run for 30 seconds, and the $20 \mathrm{~mm}$ stainless steel ball was cleaned with Isopropanol and distilled water after ever sample run. 


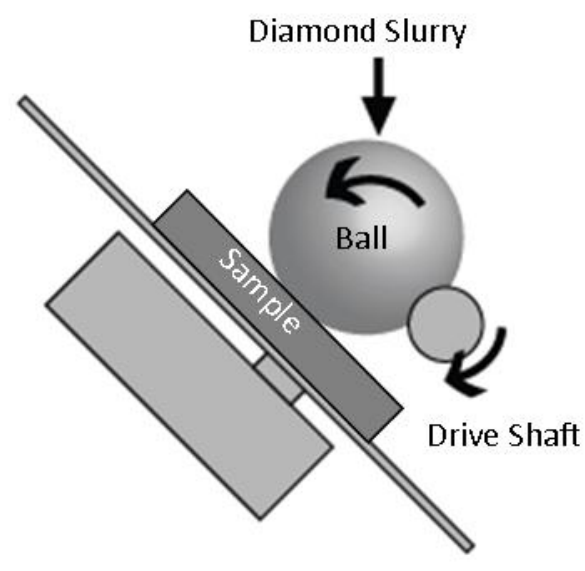

Figure 5 Schematic of CaloTest sample setup

Optical inspection of the resulting calotte using Anton Paar Video Capture Software was used in order to determine the resulting coating thickness from the projected surfaces of both the abraded coating and substrate material. In order to determine the coating thickness $(\mathrm{S})$, the video software measures the $\mathrm{X}$ and $\mathrm{Y}$ parameters labelled in Figure 6. Via the use of Equation 3.1;

$$
S=\frac{1}{2}\left(\sqrt{4 R^{2}-d^{2}}-\sqrt{4 R^{2}-D^{2}}\right)
$$

Where $\mathrm{R}$ is the radius of the ball, $\mathrm{D}$ is the total diameter of the calotte, and $\mathrm{d}$ is the diameter of the calotte of the substrate material only. The $\mathrm{X}$ and $\mathrm{Y}$ parameters can be derived in order to calculate the coating thickness from Equation 3.2;

$$
S=\frac{X Y}{2 R}
$$




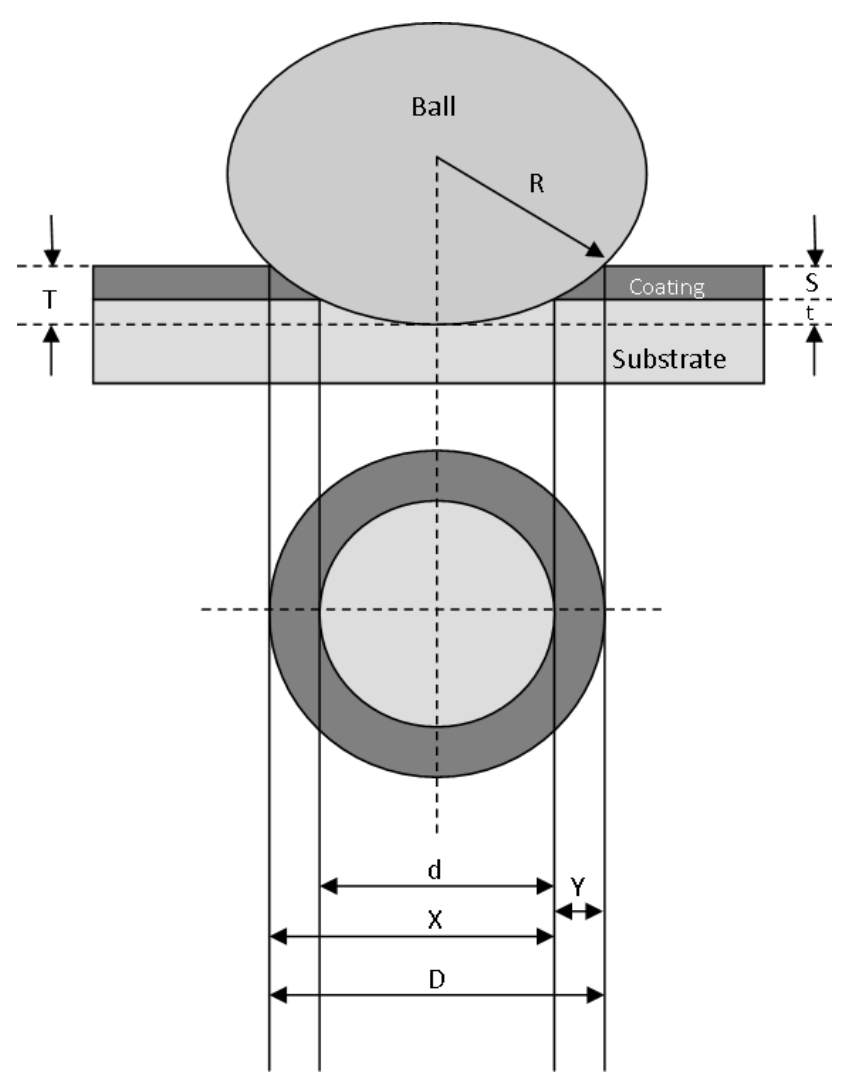

Figure 6 Schematic diagram displaying the parameters used in determining sample coating thickness using the CaloTest

\subsubsection{Optical Transmission}

The optical Transmission of the fabricated $\mathrm{ZnO}$ thin films was measured using a UV-vis spectrophotometer (Jaz Spectrometer Module, Ocean Optics, Inc., Dunedin FL) with the deuterium-tungsten halogen light source module. The optical transmission values of these film was measured between $388-892 \mathrm{~nm}$ in order to measure the transmission within the visible wavelength region $(400-800 \mathrm{~nm})$ and was calculated as a percentage of the ambient transmission. 


\subsubsection{Instrumented Indentation}

In order to investigate the surface mechanical properties of the $\mathrm{ZnO}$ thin films such as the hardness $(\mathrm{H})$ and elastic modulus $(\mathrm{E})$, the Anton Paar Nanoindentation Tester (NHT2) was used. Instrumented indentation testing is one of the most accurate and highly utilised experimental techniques when one wants to quantify the surface mechanical properties of thin films, bulk materials, and soft materials. This highly established method uses a diamond indenter tip of a known geometry, which is driven into a pre-determined specific site of the sample material by applying a linearly increasing normal load to and pre-set maximal value. Once this maximal load is reached, the load is reduced until partial or complete relaxation occurs. The resulting load/displacement curves are then analysed as they provide data that is specific to mechanical nature of the sample material under investigation. An example load/displacement curve can be seen in Figure 7. This removes the need to optically analyze the resulting residual indentation within the sample material, which was originally used to determine the Vickers Hardness of materials.This procedure often led to false results when analysing thin films, as the indentations may be difficult to see. Furthermore, during indentation testing it is imperative that the indentation depth is kept to $10 \%$ of the total coating thickness as to remove all influence from the substrate material. 


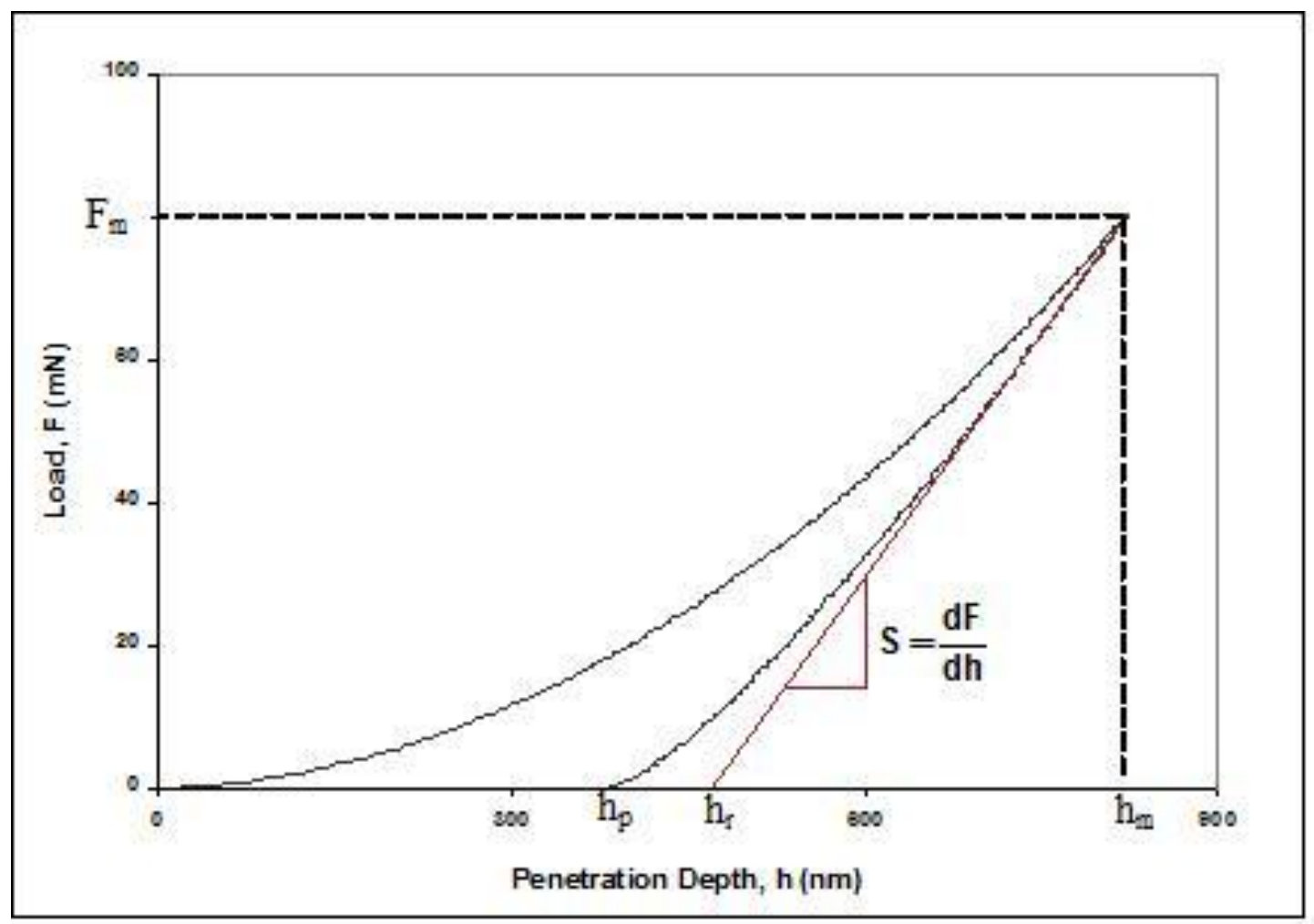

Figure 7 Instrumented Indentation Load/Displacement Curve

Through a series of mathematical equations, the Instrumented Hardness $\left(\mathrm{H}_{\mathrm{IT}}\right)$ and Instrumented Modulus ( $\left.\mathrm{E}_{\mathrm{IT}}\right)$ can be calculated. In order to determine Hardness and Elastic Modulus of the sample material, we use the Power Law Method developed by Oliver \& Pharr (Oliver and Pharr, 1992). This method describes the upper portion of the unloading curve by a power law relationship shown in Equation 3.3

$$
F=F_{\max }\left(\frac{h-h_{p}}{h_{\max }-h_{p}}\right)^{m}
$$

Where; $F$ is the test force, $F_{\max }$ is the maximal applied force, $h$ is the indentation depth under the applied test force, $h_{p}$ is the permanent indentation depth after the removal of the test force, $h_{\max }$ is the maximal indentation depth at the maximal applied force, and $m$ is the power law constant exponent. The Power Law exponent, $m$, is determined by a least squares fitting 
procedure and is a function of the indenter geometry. The contact stiffness, $S$, is derived from Equation 3.4.

$$
S=\left(\frac{d F}{d h}\right)_{\max }=m \cdot F_{\max }\left(h_{\max }-h_{p}\right)^{-1}
$$

The tangent depth, $h_{r}$, is given in Equation 3.5.

$$
\boldsymbol{h}_{r}=\boldsymbol{h}_{\max }-\frac{\boldsymbol{F}_{\max }}{\boldsymbol{S}}
$$

The contact depth, $h_{c}$, is given in equation 3.6 where $\varepsilon$ is dependent on the power law exponent $m$.

$$
h_{c}=h_{\max }-\varepsilon\left(h_{\max }-h_{r}\right)
$$

The Instrumented Hardness $\left(\mathrm{H}_{\mathrm{IT}}\right)$ is derived from the ratio between the applied load and the contact area and is expressed in Equation 3.7 where $F_{\max }$ is the maximal applied load, and $A_{p}$ is the area of contact between the indenter and the sample material at maximum depth and load. $F_{\max }$ is known from the Anton Paar Indentation Software, and $\mathrm{A}_{\mathrm{p}}$ is calculated from a known reference material such as fused silica.

$$
H_{I T}=\frac{F_{\max }}{A_{p}}
$$

A reduced modulus, $E_{r}$, is used to account for elastic displacements occurring in both the sample material, and the indenter itself and is derived by Equation 3.8 where; $\beta$ is a geometric factor depending on the diamond shape (circular: $\beta=1$, triangular: $\beta=1.034$, square: $\beta=$ 1.012) 


$$
E_{r}=\frac{\sqrt{\pi \cdot S}}{2 \cdot \boldsymbol{\beta} \cdot \sqrt{A_{p}\left(h_{c}\right)}}
$$

Having already derived the values of $S, A_{p}$, and $E_{r}$, the Instrumented Modulus, $E_{I T}$, within the sample material can then calculated from Equation 3.9. Where; $v_{i}$ is the poisons ratio of the indenter, $v_{s}$ is the poisons ratio of the sample, and $E_{i}$ is the modulus of the indenter.

$$
\frac{1}{E_{r}}=\frac{1-v_{s}^{2}}{E_{I T}}+\frac{1-v_{i}^{2}}{E_{i}}
$$

When analysing relatively soft coatings on hard substrates, such as these $\mathrm{ZnO}$ thin films on soda lime glass substrates, it is desirable to use relatively low normal loads to ensure that the penetration depths stay below the generally accepted maximum penetration depth of $10 \%$ of the total coating thickness in order avoid influence of the hard substrate. The NHT2 utilizes a unique top referencing ring in order to reduce stabilization time and negate the affects thermal drift during testing for highly accurate results. The specifications of the NHT2 can be seen in Table 1 and a schematic of the NHT2 head can be seen in Figure 8.

Table 1 NHT2 Specifications

\begin{tabular}{lll}
\hline NHT2 & Force & Depth \\
\hline Resolution & $0.01 \mu \mathrm{N}$ & $0.01 \mu \mathrm{m}$ \\
Maximum & $500 \mathrm{mN}$ & $200 \mu \mathrm{m}$ \\
\hline
\end{tabular}


During indentation testing using NHT2, the maximal normal loads ranged from $0.3-0.5 \mathrm{mN}$ in order to ensure indentation depth remained below $10 \%$ of the total thickness of the sample coating, where a thicker coating allowed for an increase in maximal load and penetration depth. The following parameters were used for all samples during instrumented indentation testing;

- Diamond Berkovich indenter tip (serial number; B-P 88)

- Approach speed/retraction speed of $2000 \mathrm{~nm} / \mathrm{min}$

- Approach distance of $2000 \mathrm{~nm}$

- Loading/unloading rate of $60 \mathrm{mN} / \mathrm{min}$

- 3 second pause once maximal normal force was reached

- Tests run in ambient air $\left(23 \pm 1^{\circ} \mathrm{C}, 40 \pm 10 \%\right.$ relative humidity $)$

- Fused Silica sample used as the reference sample

- Indentations ran inside an acoustic emission chamber

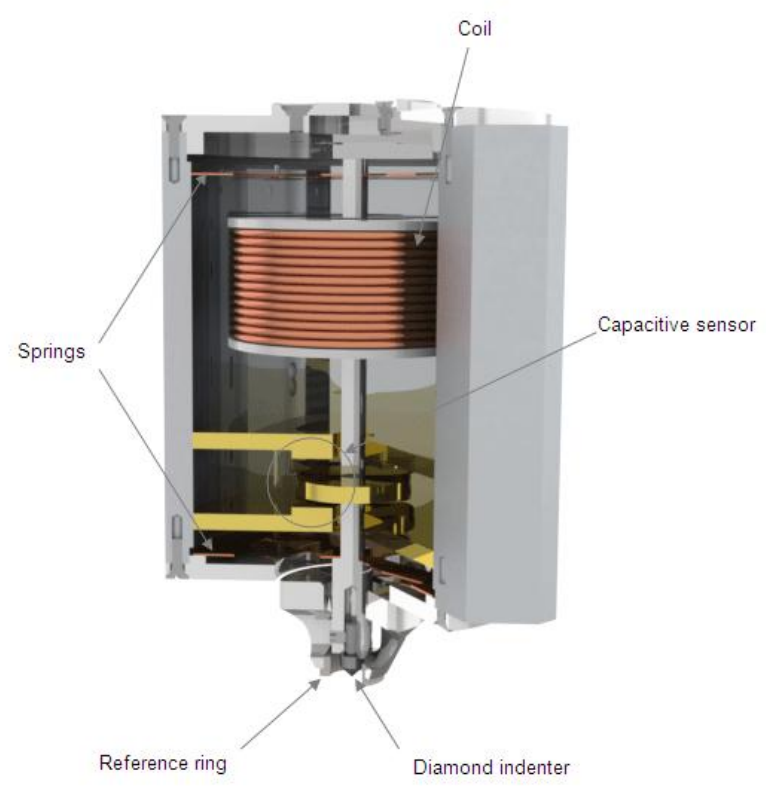

Figure 8 Schematic of NHT2 head assembly (Image courtesy of Anton Paar) 


\subsubsection{Tribological techniques}

In order to assess the tribological properties of $\mathrm{ZnO}$ thin films, the Anton Paar Standard Tribometer was used. This instrument was used to determine if the friction coefficient and/or wear characteristics were affected by an increase in annealing temperature. A spherical static partner is loaded onto the test sample, with a precisely known force. The static partner is mounted on a stiff lever, which has been designed as a frictionless transducer. As the experiment runs and the sample slides past the static partner, resulting frictional forces acting between the sample and the static partner are measured by very small deflections of the lever using a linear variable differential transformer (LVDT) sensor. The coefficient of friction can then be simply calculated as the ratio of the measured tangential force on the tribometer lever and the normal force applied The Anton Paar Tribometer can operate in both a rotational, and a linear reciprocating fashion and conforms to ASTM G99 and G133 standards. For this experiment, the linear reciprocating method was adopted in order to gain information on both the static and dynamic friction characteristics of the $\mathrm{ZnO}$ thin films. A diagram of the Tribometer setup can be seen in Figure 9.

The following parameters were used;

- A normal load of $2 \mathrm{~N}$

- $3 \mathrm{~mm}$ 100Cr6 stainless steel ball as the static partner.

- A stroke length of $4 \mathrm{~mm}$.

- A testing frequency of $1 \mathrm{~Hz}$.

- Dry sliding conditions.

- Testing at room temperature.

- Experiment ran for 600 cycles.

- Assuming totally elastic deformation 


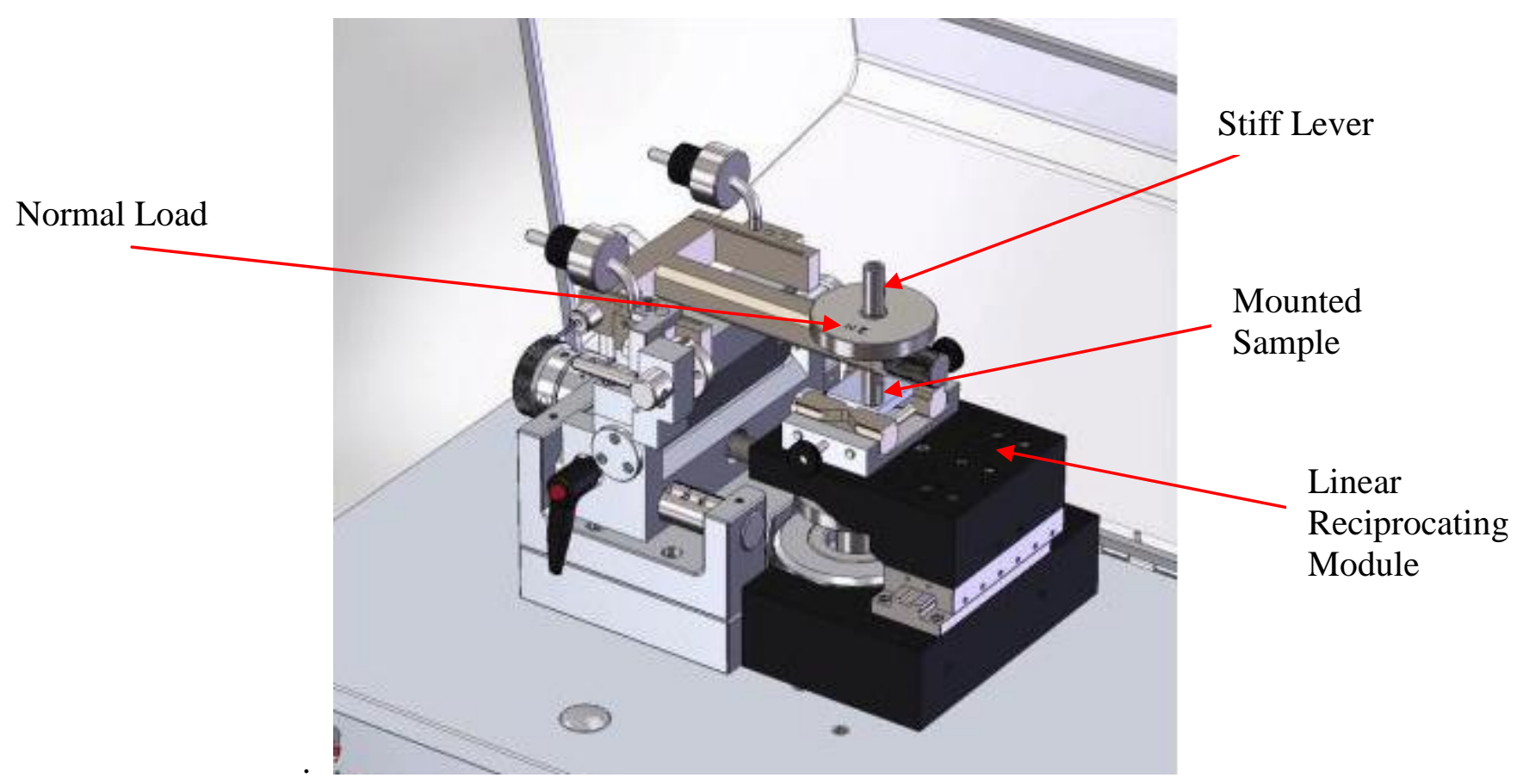

Figure 9 Anton Paar Standard Tribometer Setup (image courtesy of Anton Paar)

\subsubsection{Scratch Testing}

In order to be able to quantify coating adhesion as a result of changing annealing temperature, and to determine at which point critical load failure of the $\mathrm{ZnO}$ coating occurs. The Anton Paar Micro-Scratch Tester (MST) was used for the scratch testing technique. This automated scratch testing technique is highly advantageous as it has the ability to analyse tangential friction force, coefficient of friction, and acoustic emission at a measured penetration depth and applied normal force. This data can then be correlated to a panoramic image of the scratch itself to better detect failure mechanisms. This can be highly beneficial when analysing composite coatings as there may be multiple failure mechanisms in the coating other than adhesive failure. The scratch test principle consists of a sphero-conical stylus which is drawn across the sample material in either a constant or a linear progressive load to generate a scratch. Under progressive loading, the critical load (Lc) is defined as the smallest load at which a particular failure mode occurs. The driving forces behind these coating 
failures are a combination of elastic-plastic indentation stresses, frictional stresses, and the residual internal stresses.

The $\mathrm{ZnO}$ thin film samples were mounted on a standard resolution friction table (ST$142,0.01 \mathrm{mN}$ friction force resolution) and scratched with a $20 \mu \mathrm{m}$ sphero-conical indenter (serial number SE-A54). A progressive linearly increasing load from $30-2000 \mathrm{mN}$ over a scratch length of $1 \mathrm{~mm}$, with a loading rate of $4000 \mathrm{mN} / \mathrm{min}$ was adopted with a $30 \mathrm{~Hz}$ acquisition rate. All measurements were conducted in ambient air $\left(23 \pm 1^{\circ} \mathrm{C}, 40 \pm 10 \%\right.$ relative humidity). Figure 10 displays a schematic diagram of the MST's components, and the sample setup under the MST can be seen in Figure 11.

Table 2 MST specifications

\begin{tabular}{llll}
\hline MST & Force & Depth & Friction \\
\hline Resolution & $0.3 \mathrm{mN}$ & $0.3 \mathrm{~nm}$ & $0.3 \mathrm{mN}$ \\
Minimum & $0.3 \mathrm{mN}$ & $0.3 \mathrm{~nm}$ & $0.3 \mathrm{mN}$ \\
Maximum & $30 \mathrm{~N}$ & $1 \mathrm{~mm}$ & $30 \mathrm{~N}$ \\
\hline
\end{tabular}




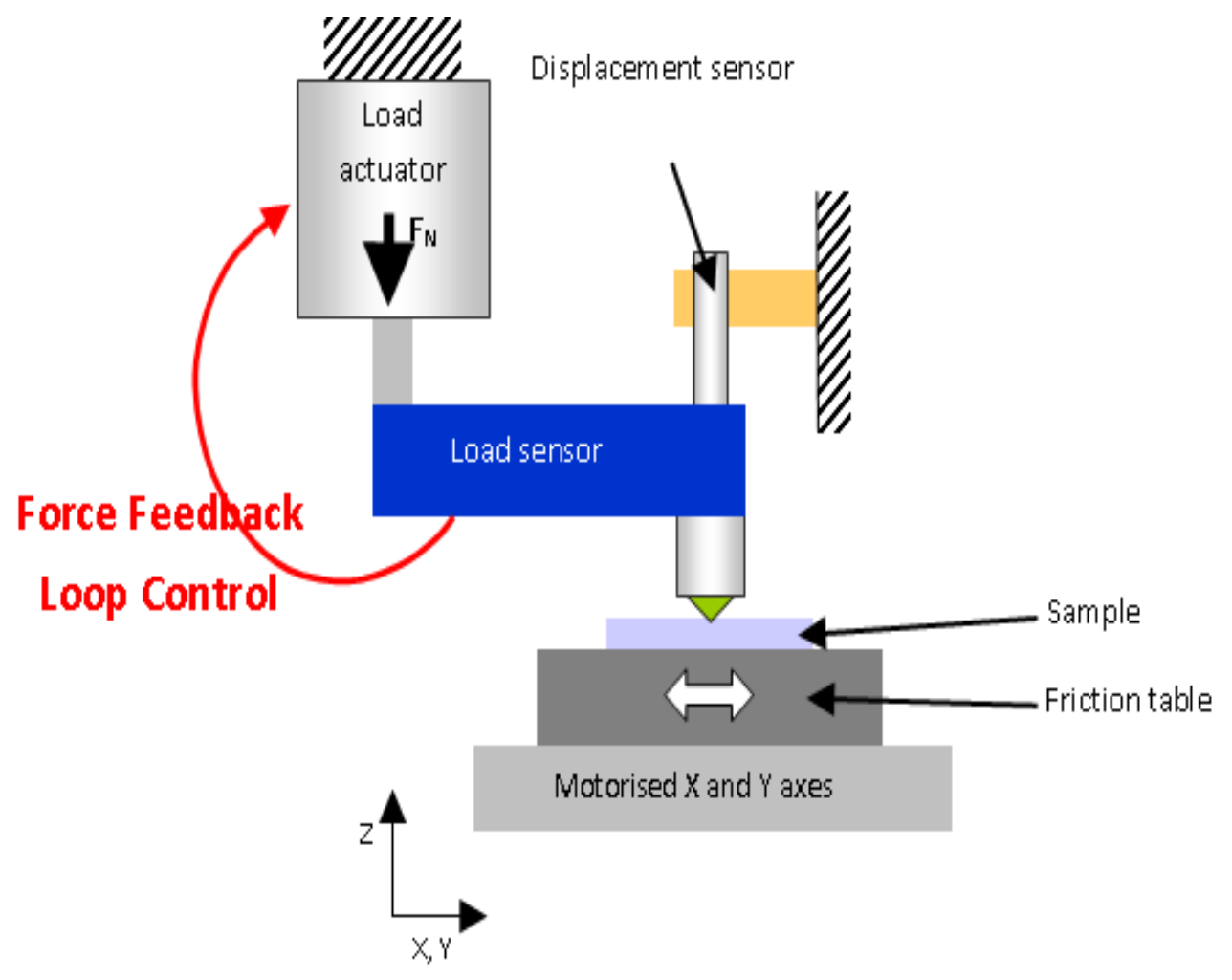

Figure 10 Schematic diagram of MST functional components

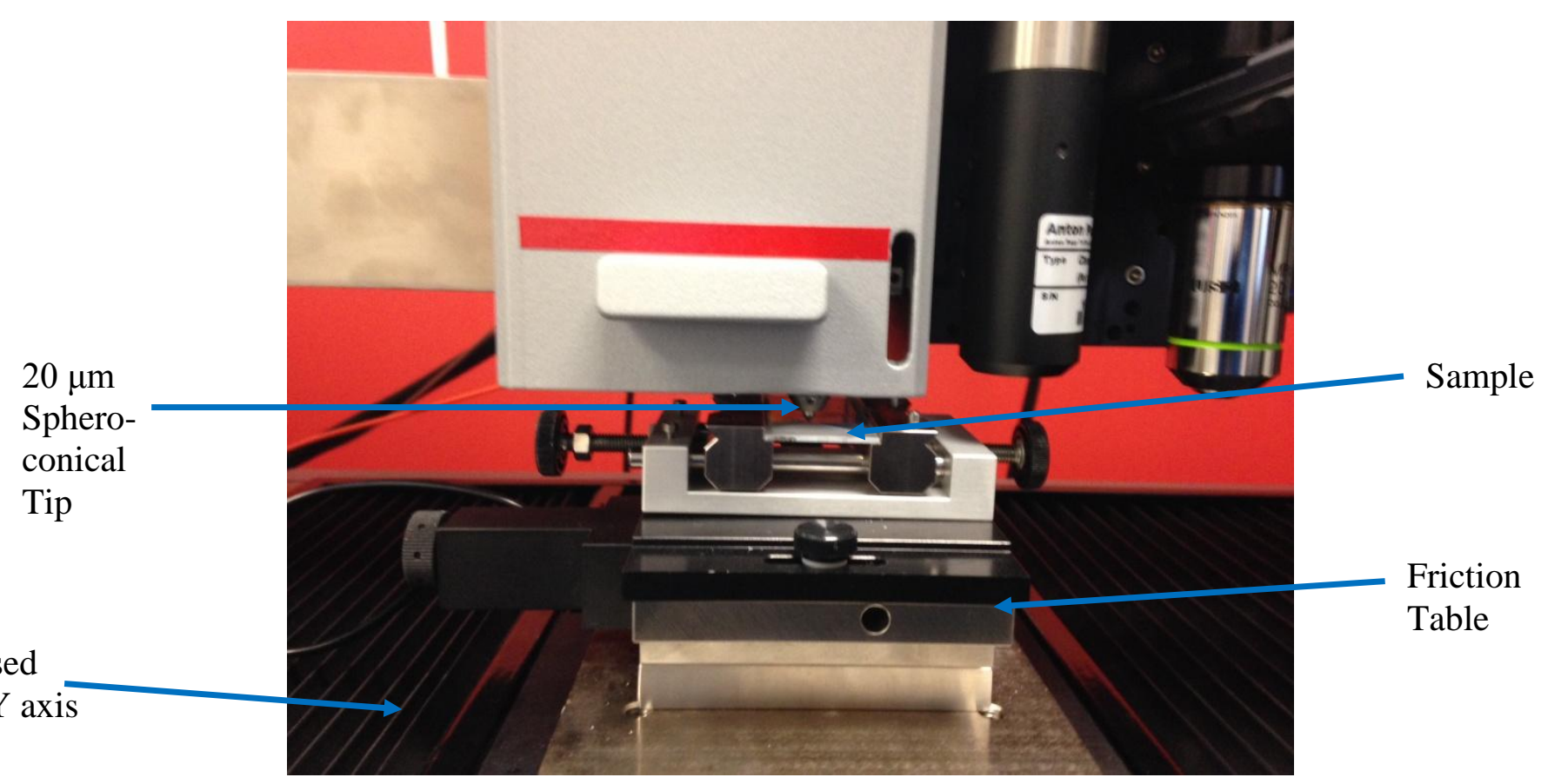

Figure 11 Image of the sample mounting setup for $\mathrm{ZnO}$ thin film under MST investigation 


\subsection{Surface analysis}

\subsubsection{Scanning Electron Microscopy (SEM)}

The SEM was used in this project to investigate the surface morphology of the samples. SEM is a widely known technique that is commonly used in modern laboratories as it is able to produce a high lateral resolution with a combined good depth of focus. A conventional Hitachi S-4700 with a tungsten gun was used for surface analysis. Analysis was conducted with a working distance that was set to equal $12 \mathrm{~mm}$ and the voltage can be changed between $0.5-30 \mathrm{KV}$, however a standard voltage of $10 \mathrm{KV}$ was adopted. Prior to SEM analysis the samples were; gold sputter coated, placed onto an SEM 'stub' and adhered with a carbon adhesive disk prior to investigation. A thin copper strip was also placed across the surface of the sample to ensure a continuous electrical path from the sample to the 'stub'. 


\section{Results and discussion}

\subsection{Optical and structural analysis}

\subsubsection{X-ray diffraction}

All samples were placed in the Bruker D8 Discover XRD system in order gain an understanding of any changes to the $\mathrm{ZnO}$ film microstructure as a result of increasing annealing temperature. Samples were placed onto a goniometer, which allowed the sample to be positioned accurately within the XRD system and rotated whilst being irradiated by a monochromatic x-ray.

From the x-ray diffraction spectra's displayed in Figure 12 Figure 13 it can be observed that all samples exhibit well ordered polycrystalline $\mathrm{ZnO}$ films with a hexagonal wurtzite structure. All samples displayed strong (001), (002) and (101) main peak intensities, with the $0.5 \mathrm{M} 500^{\circ} \mathrm{C}$ samples showing strong preferential growth along the c-axis $(002)$ plane, which is known to indicate piezoelectric film properties (Kiriakidis et al., 2014). It can also be seen that as the annealing temperature is increased, the intensity of the XRD spectra peaks can also be seen to increase indicating an increase in film crystallinity. These phenomena can be seen more readily in Figure 13 , where the $0.75 \mathrm{M} 600^{\circ} \mathrm{C}$ samples showed significantly higher peak intensities, than that of the $0.75 \mathrm{M} 500^{\circ} \mathrm{C}$ samples. These results indicate that both the zinc concentration and annealing temperature affect the $\mathrm{ZnO}$ film growth mechanisms. This can be attributed to an increase in the $\mathrm{Zn}^{2+}$ species available to facilitate well ordered $\mathrm{ZnO}$ film growth as the initial zinc concentration of the sol is increased, and the increase in annealing temperature enhances $\mathrm{ZnO}$ film crystallinity whilst increasing grain size. These results are in accordance with previous work by Shinde et al., (2007) that 
indicated that zinc concentration has a significant effect on $\mathrm{ZnO}$ film growth, and that peak intensities may increase with increasing annealing temperature (Shinde et al., 2007, Lin and Kim, 2009) .

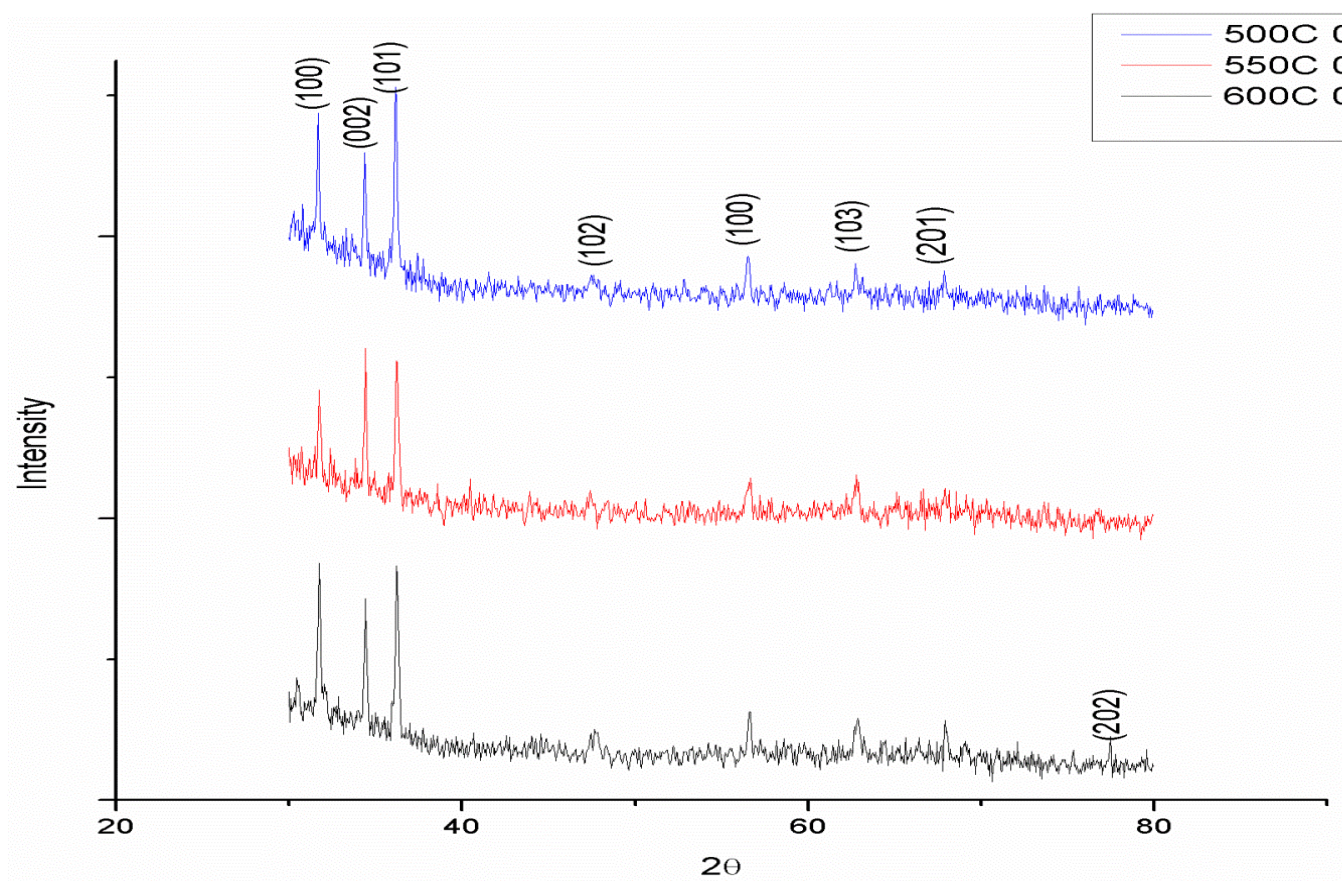

Figure 12 XRD spectra of $0.5 \mathrm{M} \mathrm{ZnO} \mathrm{films} \mathrm{annealed} \mathrm{at} \mathrm{500,} \mathrm{550,} \mathrm{and} 600^{\circ} \mathrm{C}$

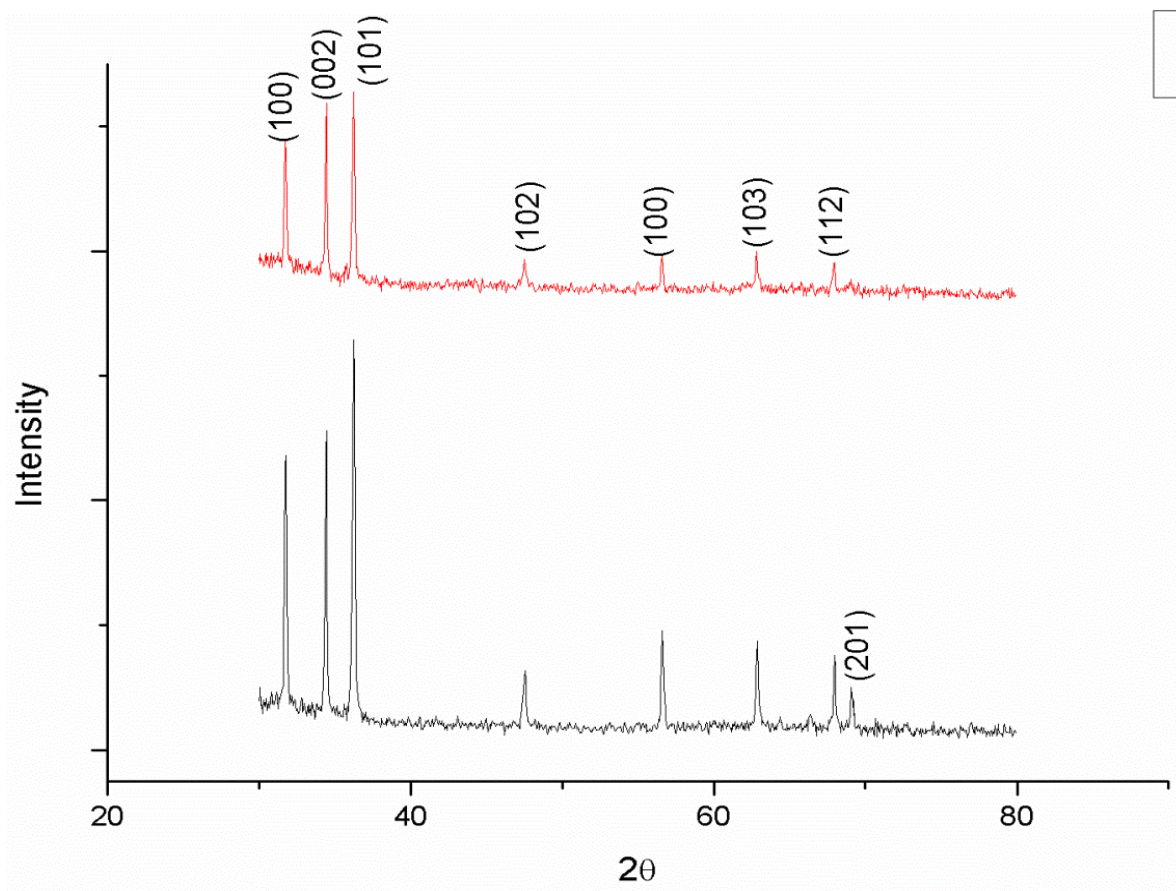

Figure $13 \mathrm{XRD}$ spectra of $0.75 \mathrm{M} \mathrm{ZnO}$ films annealed at 500, and $600^{\circ} \mathrm{C}$ 


\subsubsection{Coating thickness}

As covered in section 3.2.2 the Anton Paar CaloTest was used to investigate how annealing temperature may affect the thickness of $\mathrm{ZnO}$ films grown on glass substrates. All 25 samples were placed under CaloTest analysis and multiple calottes were run at different locations across the sample in order to account for any variations of the film thickness across the total sample area. After the CaloTest experimental procedure is completed, video software is then used to analyse the coating and display the resultant film thickness through calculations described in section 3.2.2 given a ball of a known geometry. An overview of this process can be seen in Figure 14.
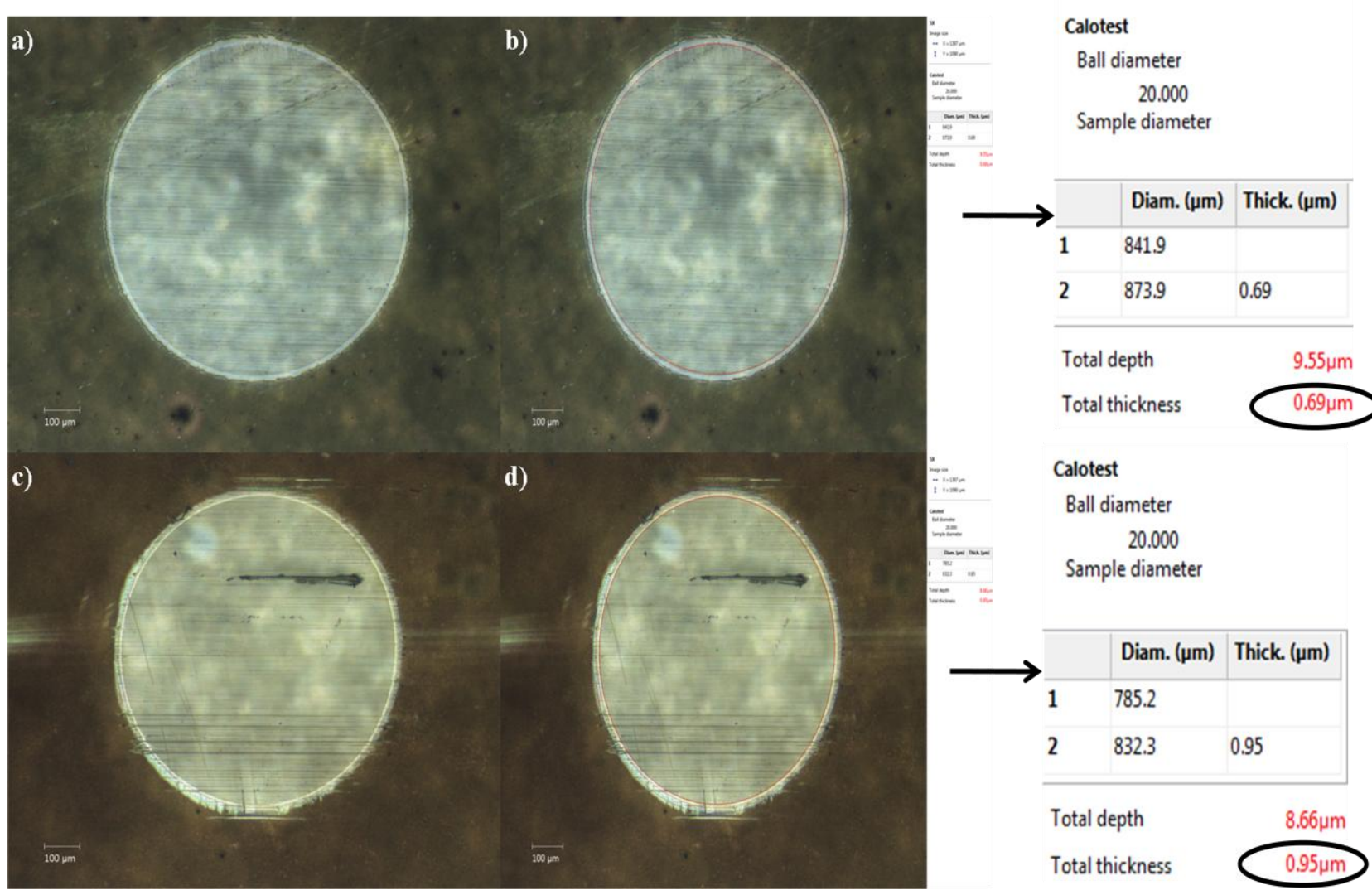

Figure 14 Overview of the Anton Paar CaloTest results analysis where; a) and b) are the original and analysed images of the $0.75 \mathrm{M} 500^{\circ} \mathrm{C}$ sample, c) and d) are the original and analysed image of the $0.75 \mathrm{M} 600{ }^{\circ} \mathrm{C}$ sample respectively. 
As a result of this analytical technique we can see that zinc concentration has a direct effect on the $\mathrm{ZnO}$ film thickness, as the thickness of samples annealed at $500^{\circ} \mathrm{C}$ and $600^{\circ} \mathrm{C}$ increased from $0.57 \pm 0.07$ to $0.67 \pm 0.12 \mu \mathrm{m}$, and $0.66 \pm 0.17$ to $0.89 \pm 0.07 \mu \mathrm{m}$ respectively when the zinc concentration was increased from $0.5 \mathrm{M}$ to $0.75 \mathrm{M}$. Furthermore, the results indicated that by increasing the annealing temperature from $500^{\circ} \mathrm{C}$ to $600^{\circ} \mathrm{C}$ the resultant film thickness would also increase, complementing our findings by XRD microstructural analysis. Samples with a sol concentration of both $0.5 \mathrm{M}$ and $0.75 \mathrm{M}$ displayed an increase in film thickness as the annealing temperature increased from $500^{\circ} \mathrm{C}$ to $600^{\circ} \mathrm{C}$ where; the thickness was seen to change from $0.57 \pm 0.07$ to $0.66 \pm 0.17 \mu \mathrm{m}$ and from $0.67 \pm 0.12$ to $0.89 \pm 0.07 \mu \mathrm{m}$ for $0.5 \mathrm{M}$ and $0.75 \mathrm{M}$ samples respectively. However, it should also be noted that there was no significant change in $\mathrm{ZnO}$ film thickness as the annealing temperature was increased from $500^{\circ} \mathrm{C}$ to $550^{\circ} \mathrm{C}$, where it actually decreased slightly $(0.57 \pm 0.07$ to $0.53 \pm 0.05 \mu \mathrm{m})$. Although this small decrease is not seen to be statistically significant, this indicates that there seems to be an optimum temperature between $550^{\circ} \mathrm{C}$ and $600^{\circ} \mathrm{C}$ which initiates the facilitation of $\mathrm{ZnO}$ film growth. Figure 15and Table 3 provide a clear overview of our findings, displaying the mean data of $\mathrm{ZnO}$ film thickness which is seen to increase as the annealing temperature is raised to $600^{\circ} \mathrm{C}$. 


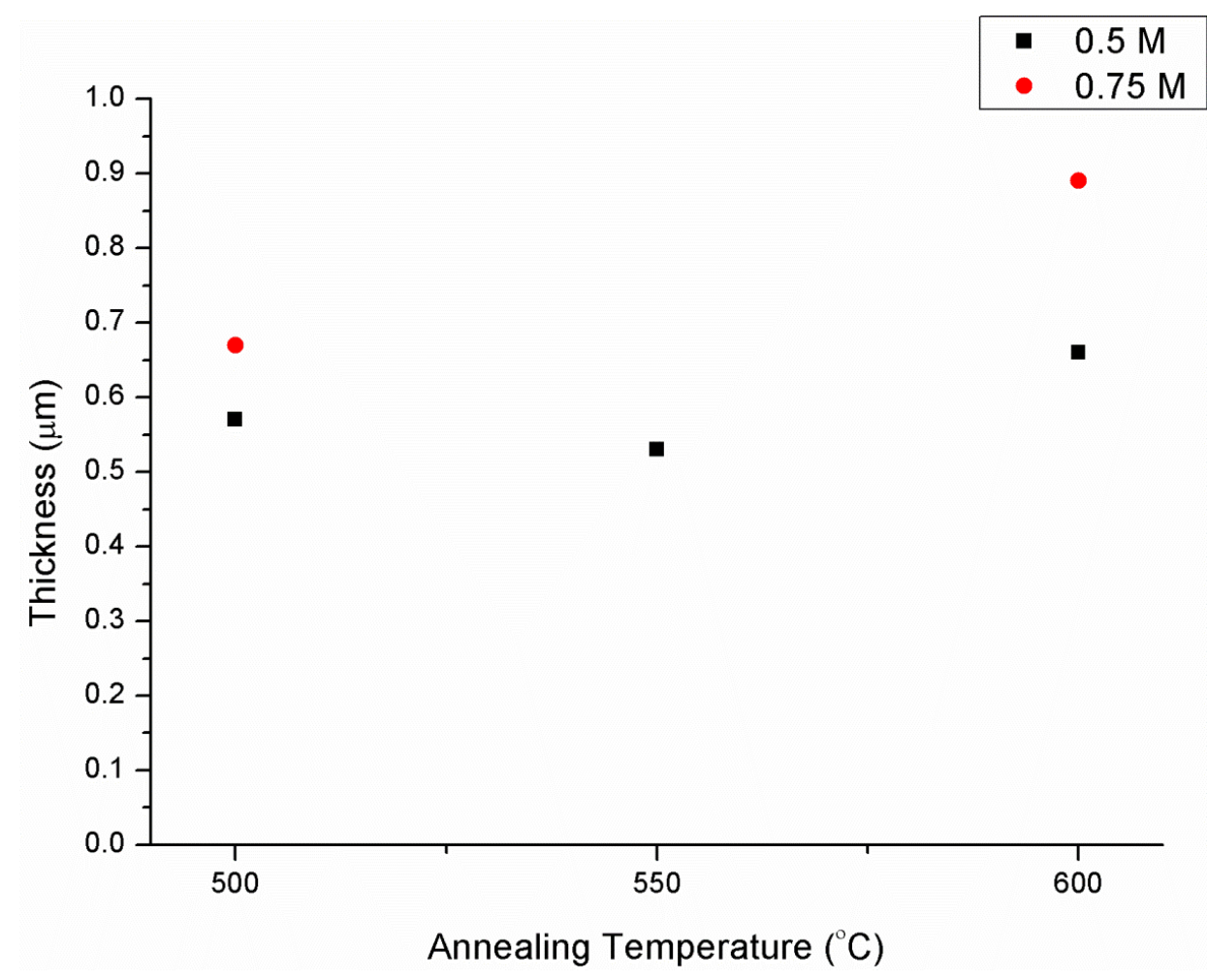

Figure 15 Mean results displaying the effect of annealing temperature on $\mathrm{ZnO}$ film thickness

Table 3 Summery of mean $\mathrm{ZnO}$ film thickness values $(\mu \mathrm{m})$ from $500^{\circ} \mathrm{C}$ to $600^{\circ} \mathrm{C}$

\begin{tabular}{llll}
\hline Concentration & $\mathbf{5 0 0}^{\mathbf{}} \mathbf{C}$ & $\mathbf{5 5 0}^{\circ} \mathbf{C}$ & $\mathbf{6 0 0}^{\circ} \mathbf{C}$ \\
\hline $\mathbf{0 . 5} \mathbf{M}$ & $0.57 \pm 0.07$ & $0.53 \pm 0.05$ & $0.66 \pm 0.17$ \\
$\mathbf{0 . 7 5} \mathbf{M}$ & $0.67 \pm 0.12$ & N/A & $0.89 \pm 0.07$ \\
& & & \\
\hline
\end{tabular}




\subsubsection{Optical properties}

Samples were placed under optical examination using a UV-vis Spectrophotometer which has been previously discussed in section 3.2.3. Figure 16 displays how annealing temperature can affect the optical transmission of $\mathrm{ZnO}$ films within the wavelength range of 400 to $900 \mathrm{~nm}$. It can be seen that as the annealing temperature is increased, the optical transmission of the $\mathrm{ZnO}$ films is significantly reduced. This investigation found that optical transmission was reduced from $73 \%$ to $66 \%$ for the $0.5 \mathrm{M}$ samples as the annealing temperature was increased from $500^{\circ} \mathrm{C}$ to $600^{\circ} \mathrm{C}$. This trend was also displayed for the $0.75 \mathrm{M}$ samples, where optical transmission was reduced from $56 \%$ to just $44 \%$. This reduction in optical transmission however does not occur solely as a direct result of increasing annealing temperature, but of the increasing $\mathrm{ZnO}$ film thickness. It has been previously discussed that both zinc concentration and annealing temperature have resulted in an increase of the $\mathrm{ZnO}$ film thickness. Therefore this increase can be seen to affect the optical transmission of these films, indicating that the optical properties of these films are dependent upon the $\mathrm{ZnO}$ film thickness where a thicker film, such as the $0.75 \mathrm{M} 600^{\circ} \mathrm{C}$ sample, results in significantly reduced optical transmission in the visible wavelength region. Table 4 displays the mean optical transmission values for all samples tested during this investigation. It can be observed that although optical transmission has decreased slightly from $73 \%$ to $70 \%$ as the annealing temperature is increased from $500^{\circ} \mathrm{C}$ to $550^{\circ} \mathrm{C}$, this decrease is not seen to be significant. This reinforces the earlier statement that there seems to be an optimal annealing temperature between $550^{\circ} \mathrm{C}$ and $600^{\circ} \mathrm{C}$ that facilitates the growth mechanisms of $\mathrm{ZnO}$ films. Additionally, spikes in the transmission spectra's can be seen for all samples in Figure 16 which can be attributed to localised vacancies within the $\mathrm{ZnO}$ microstructure which cause scattering (Mikhail F. Limonov, 2012). 


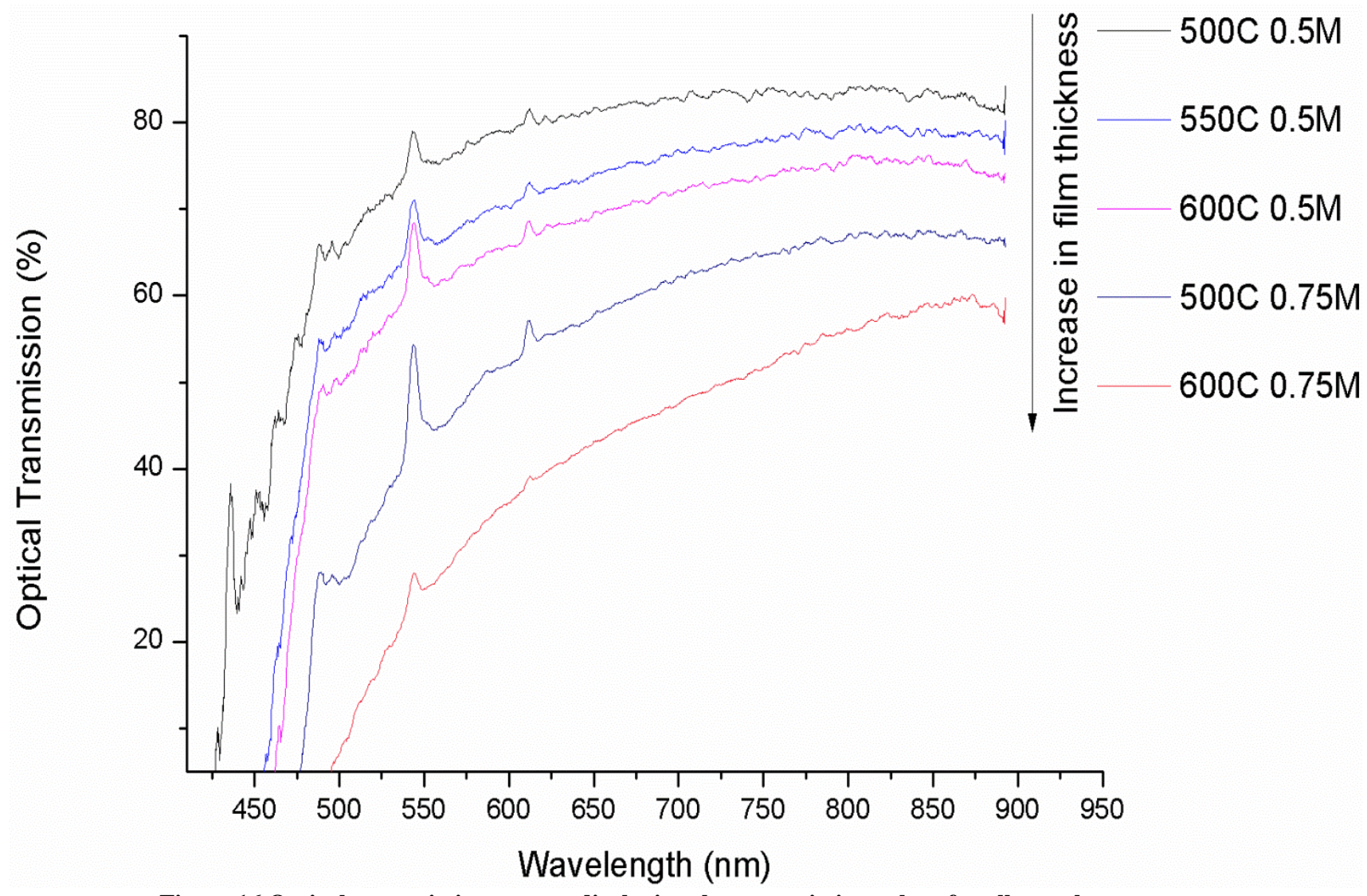

Figure 16 Optical transmission spectra displaying the transmission values for all samples

Table 4 Mean optical transmission values 350 - 920 nm (\%)

\begin{tabular}{llll}
\hline Concentration & $\mathbf{5 0 0}^{\mathbf{}} \mathbf{C}$ & $\mathbf{5 5 0}^{\mathbf{}} \mathbf{C}$ & $\mathbf{6 0 0}^{\mathbf{}} \mathbf{C}$ \\
\hline $\mathbf{0 . 5} \mathbf{M}$ & $73.47 \pm 4.04$ & $70.18 \pm 2.5$ & $66.75 \pm 3.11$ \\
$\mathbf{0 . 7 5} \mathbf{M}$ & $56.96 \pm 1.42$ & N/A & $44.78 \pm 3.63$ \\
& & & \\
\hline
\end{tabular}




\subsection{Mechanical properties}

\subsubsection{Hardness and elastic modulus}

Instrumented nanoindentation was conducted on all samples using the Anton Paar Nanoindentation Tester that has been previously described in section 3.2.4, in order to analyse the hardness and elastic moduli of $\mathrm{ZnO}$ films annealed at $500^{\circ} \mathrm{C}, 550^{\circ} \mathrm{C}$ and $600^{\circ} \mathrm{C}$. In order to gain a greater understanding of the $\mathrm{ZnO}$ films mechanical properties and to ensure reliable results, matrices of indents were performed on several areas of the $\mathrm{ZnO}$ films. Furthermore, to remove the influence of substrate effect the maximum indentation depth for each indent was limited to less than $10 \%$ of the films total thickness. A maximum load of $0.5 \mathrm{mN}$ was found to be sufficient in gaining reliable data whilst maintaining a penetration depth of less than $10 \%$ of the films thickness. Figure 17 displays representative indentation matrix of load distribution curves whilst remaining bellow the designated $10 \%$ threshold.
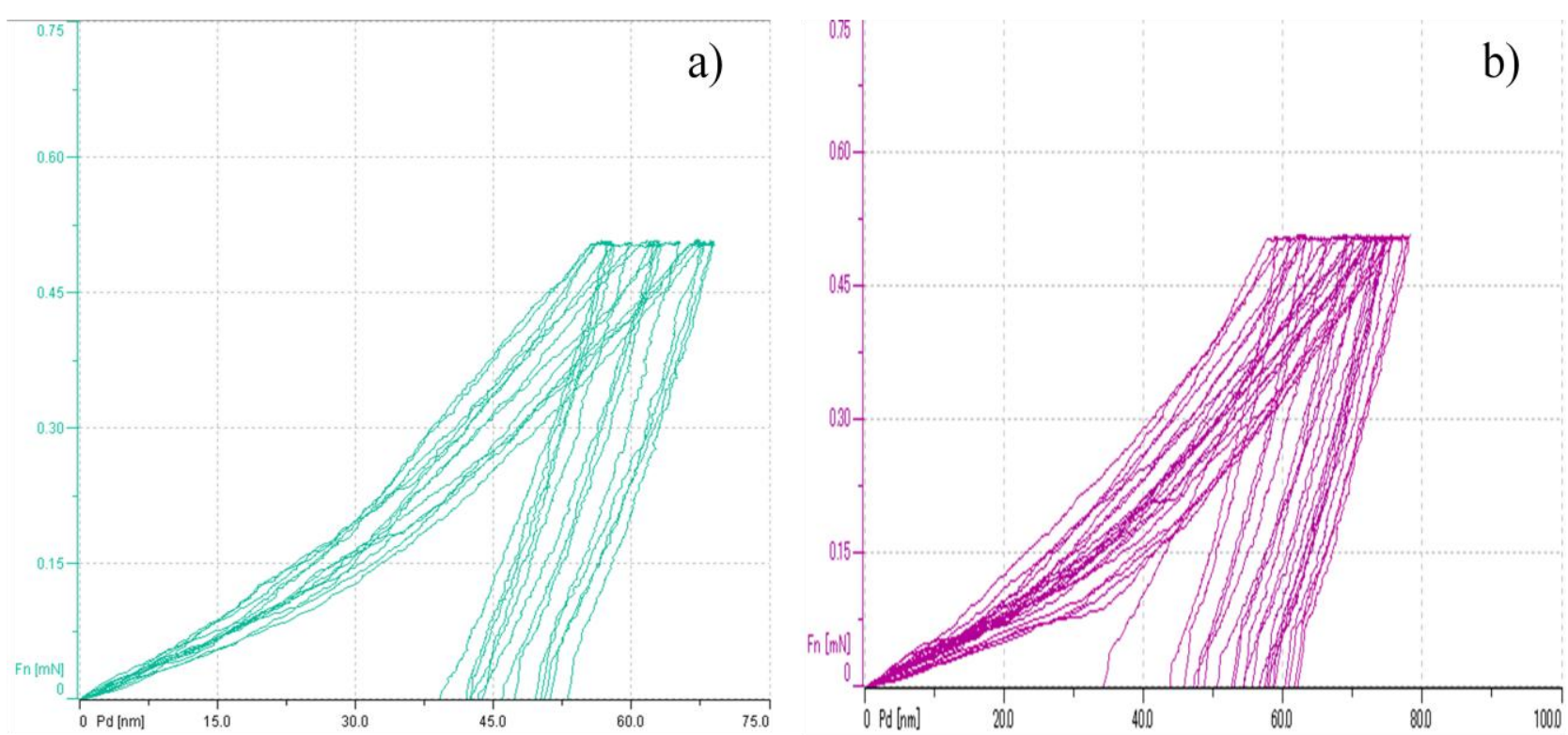

Figure 17 Representative normal load-penetration depth curves of a standard indentation matrix for; a) $0.75 \mathrm{M} 500^{\circ} \mathrm{C}$, and b) $0.75 \mathrm{M} 600^{\circ} \mathrm{C}$ samples. 
The Berkovich indenter tip was used to measure the hardness and elastic moduli of all $\mathrm{ZnO}$ films. The hardness results of these films can be seen in Figure 18 and Table 5. The highest mean hardness value, $2.76 \pm 0.71 \mathrm{GPa}$, was seen for the $0.75 \mathrm{M} 600^{\circ} \mathrm{C}$ sample group, whereas the lowest mean hardness, $1.79 \pm 0.57 \mathrm{Gpa}$, was displayed within the $0.5 \mathrm{M} 500^{\circ} \mathrm{C}$ sample group. Analysis of Table 5 and Figure 18 indicates that as both the annealing temperature, and zinc concentration increases, the hardness of the $\mathrm{ZnO}$ films increase also. Although previously increasing the annealing temperature from $500^{\circ} \mathrm{C}$ to $550^{\circ} \mathrm{C}$ had not been seen to significantly affect the thickness of the $\mathrm{ZnO}$ films, through indentation testing it can be seen that this $50^{\circ} \mathrm{C}$ increase in annealing temperature can result in an increase of $\mathrm{ZnO}$ film hardness. Thus, indicating that the hardness of $\mathrm{ZnO}$ films is somewhat dependant on the annealing temperature. This is due to the increase in crystallinity and well ordered $\mathrm{ZnO}$ film growth, which was displayed via the increase in peak intensities displayed in Figure 12Figure 13.

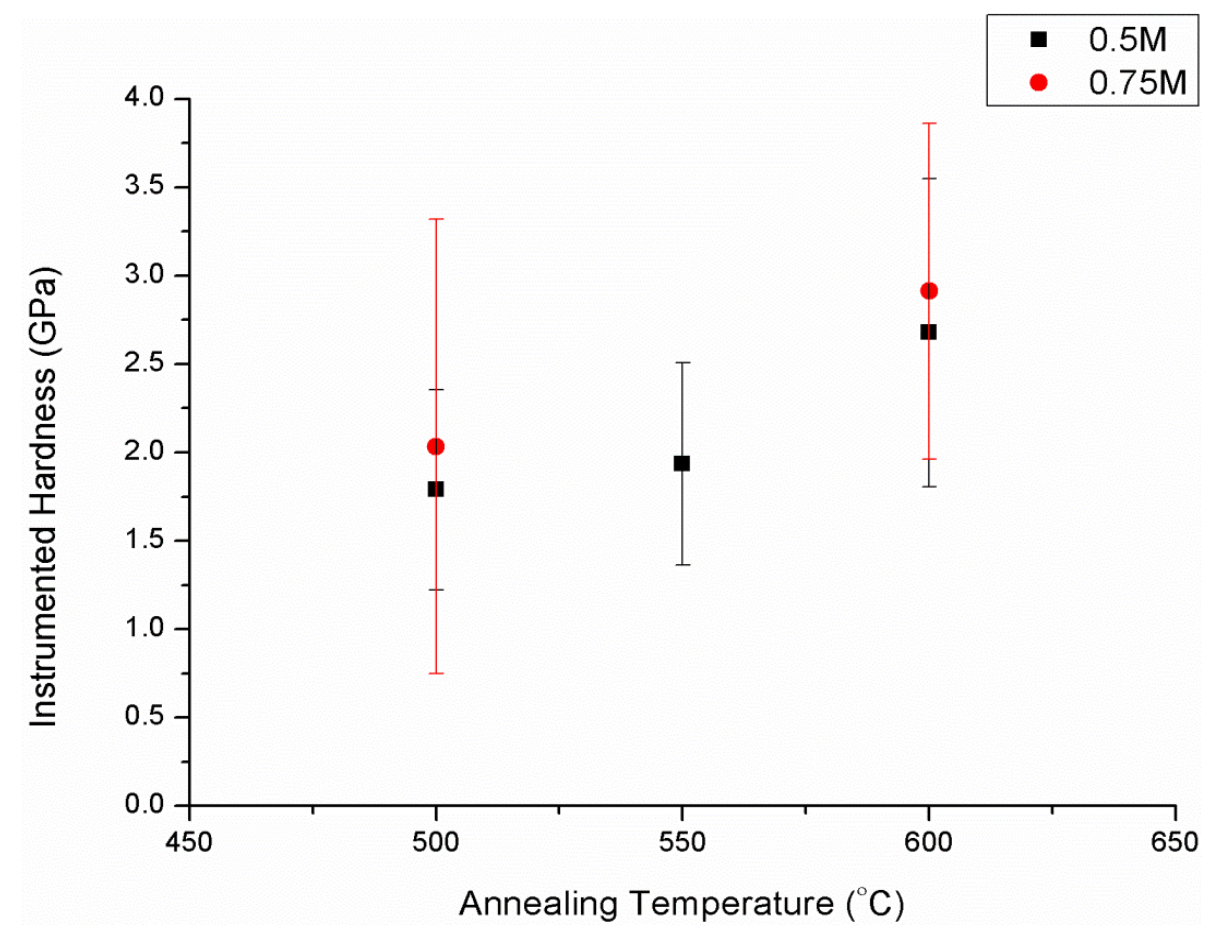

Figure 18 Instrumented hardness values of $\mathrm{ZnO}$ films at $500^{\circ} \mathrm{C}, 550^{\circ} \mathrm{C}$, and $600^{\circ} \mathrm{C}$ 
Table 5 Mean Instrumented Hardness values (GPa)

\begin{tabular}{llll}
\hline Concentration & $\mathbf{5 0 0}^{\circ} \mathbf{C}$ & $\mathbf{5 5 0}^{\circ} \mathbf{C}$ & $\mathbf{6 0 0}^{\mathbf{}} \mathbf{C}$ \\
\hline $\mathbf{0 . 5} \mathbf{M}$ & $1.79 \pm 0.57$ & $1.94 \pm 0.57$ & $2.68 \pm 0.87$ \\
$\mathbf{0 . 7 5} \mathbf{M}$ & $2.03 \pm 1.29$ & N/A & $2.76 \pm 0.71$ \\
& & & \\
\hline
\end{tabular}

In addition to gaining an indication of the $\mathrm{ZnO}$ films hardness, nanoindentation testing is also enabling us to identify the films elastic modulus. Similarly, the elastic moduli of $\mathrm{ZnO}$ films can also be seen to increase as the annealing temperature increases; $70.19 \pm 17.89$, $72.34 \pm 12.04,73.72 \pm 11.84$ for the $0.5 \mathrm{M}$ sample group at $500^{\circ} \mathrm{C}, 550^{\circ} \mathrm{C}$ and $600^{\circ} \mathrm{C}$ respectively. However, unlike the previous seen within the hardness values, the increase zinc concentration was not shown to affect the $\mathrm{ZnO}$ films elastic moduli. The increase in elastic moduli due to the increase in annealing temperature can be found within Figure 19 and Table 6. It is also important to note the high standard deviation associated with the elastic moduli results. This can be an indication of surface roughness and/or porosity which can affect the instrumented indentation results depending upon the localised area of contact.

Table 6 Mean Instrumented Modulus values (GPa)

\begin{tabular}{llll}
\hline Concentration & $\mathbf{5 0 0}^{\mathbf{}} \mathbf{C}$ & $\mathbf{5 5 0}^{\mathbf{}} \mathbf{C}$ & $\mathbf{6 0 0}^{\mathbf{}} \mathbf{C}$ \\
\hline $\mathbf{0 . 5} \mathbf{M}$ & $70.19 \pm 17.89$ & $72.34 \pm 12.04$ & $73.72 \pm 11.84$ \\
$\mathbf{0 . 7 5} \mathbf{M}$ & $69.80 \pm 14.40$ & N/A & $71.38 \pm 14.00$ \\
\hline
\end{tabular}




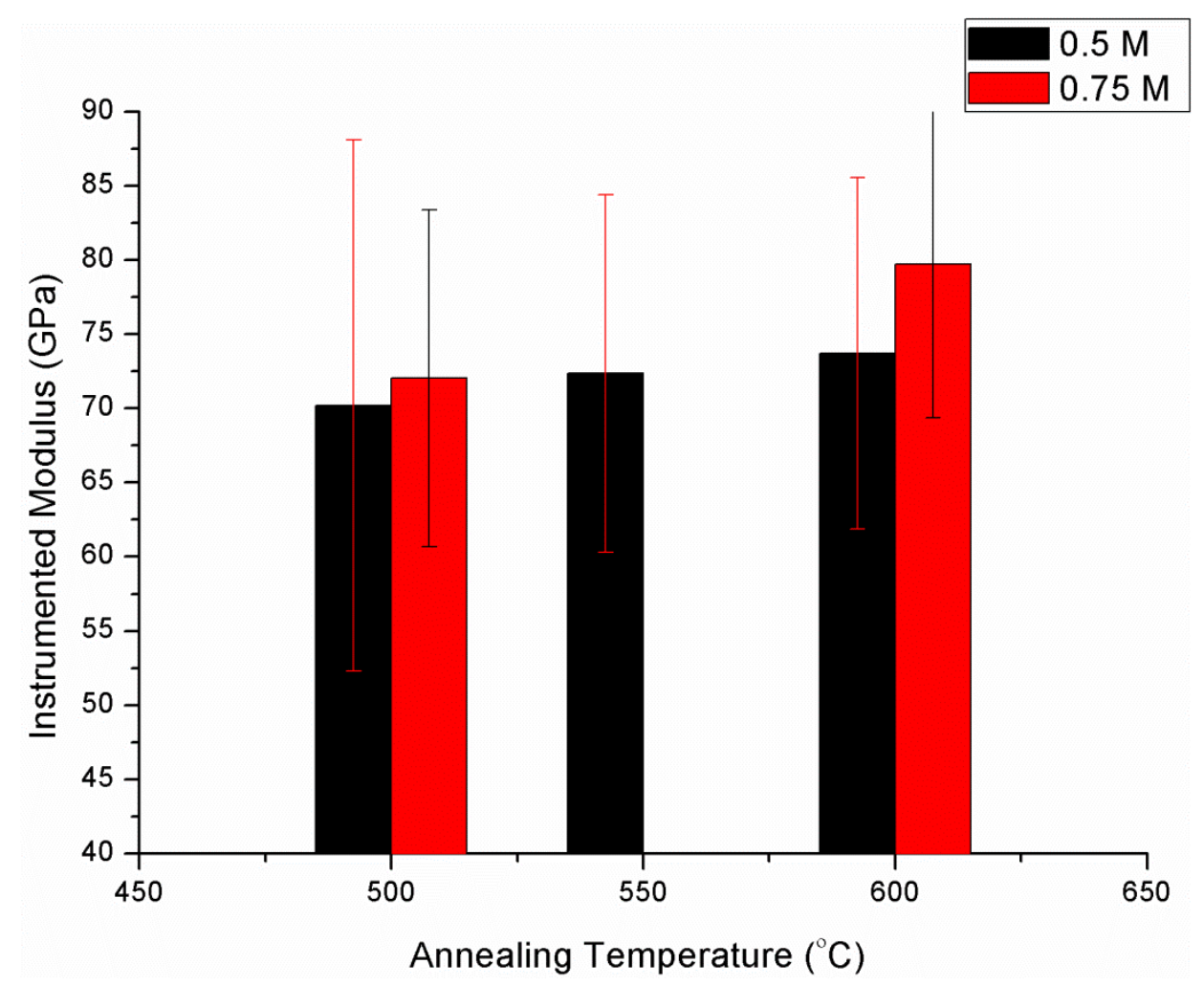

Figure 19 Instrumented modulus values of $\mathrm{ZnO}$ films at $500^{\circ} \mathrm{C}, 550^{\circ} \mathrm{C}$, and $600^{\circ} \mathrm{C}$ 


\subsubsection{Scratch resistance}

The Anton Paar Micro-Scratch Tester (MST) was utilised in order to gain insight into the adhesion strength, as well as the cohesive and adhesive failure mechanisms of the $\mathrm{ZnO}$ coating. A linear progressive load was applied from 0.3 to $2 \mathrm{~N}$ over a $1 \mathrm{~mm}$ scratch length for all samples, using a $20 \mu \mathrm{m}$ diamond sphero-conical tip. As the scratch progresses across the sample, multiple data sets are recoded including; penetration depth, friction co-efficient, tangential (frictional) force, and acoustic emission. Once the scratch has been completed the indenter is run over the scratch path at a low load in order to measure the elastic recovery (residual depth) of scratch. Figure 20 displays this data from 3 individual scratches of the $0.5 \mathrm{M} 550^{\circ} \mathrm{C}$ sample. It can be seen that the data is highly reproducible which allows for highly accurate result data sets. The samples were then placed under an optical microscope for visual analysis. Utilising all the data at hand enables one to determine critical failure loads at which the $\mathrm{ZnO}$ coating is subjected to cohesive or adhesive failure as a result of stresses induced from scratch testing.

At lower load regimes, these stresses result in conformal cracking of the coating which still remains fully adherent. The onset of these phenomena is defined as the first critical load, LC1. In the higher load regimes, other critical loads can be correspond to the onset of coating detachment from the substrate material by tunnelling crack formation, delamination, buckling, or chipping failure mechanisms and are known as LC2, and LC3. These critical load failure mechanisms can be seen in Figure 21, where the magnified images of LC1 and LC2 mechanisms can be seen to show cohesive tensile cracking, and tunnelling crack formation respectively. The final critical load failure, LC3, depicts total coating delamination and chipping. 


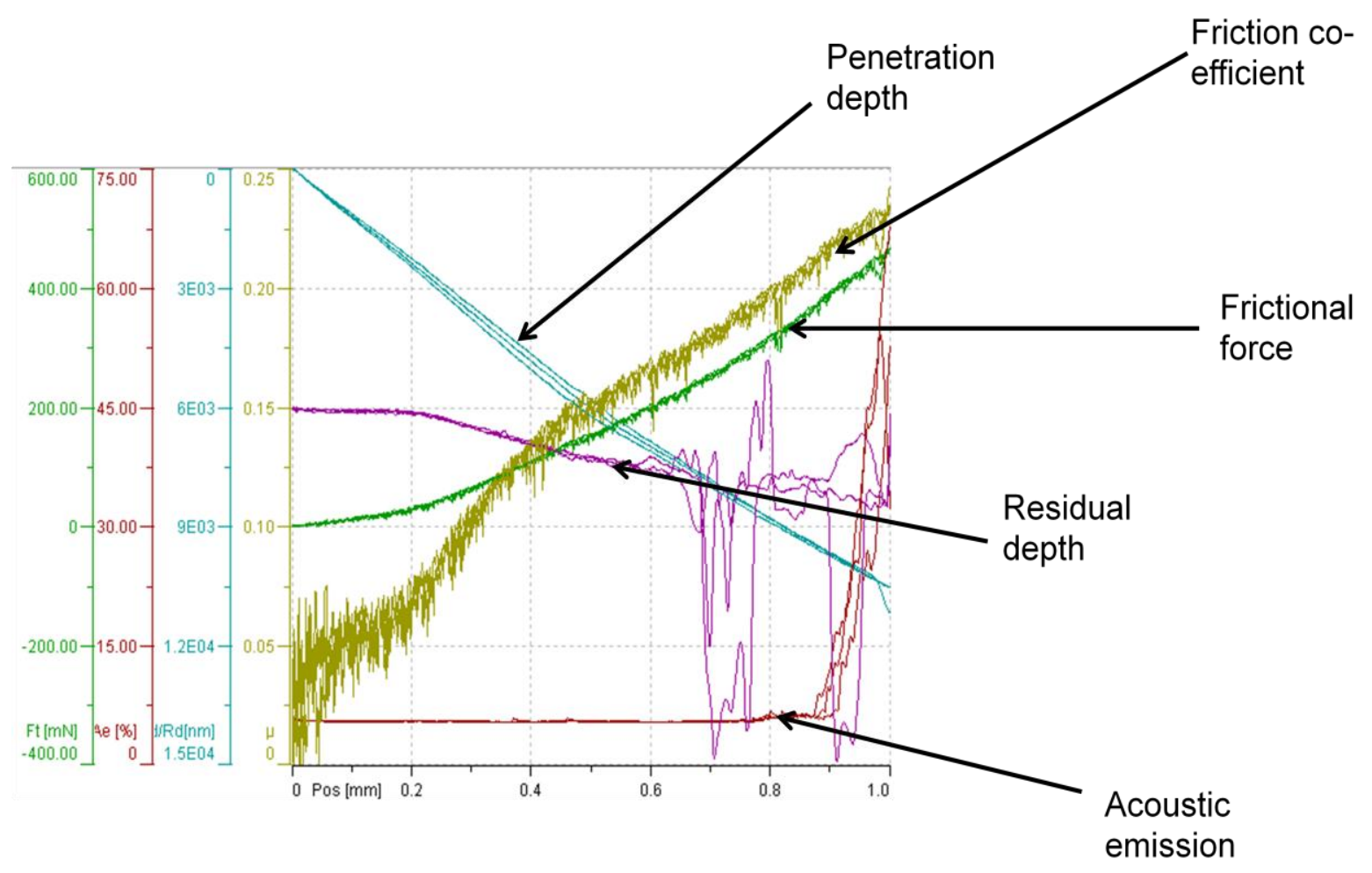

Figure 20 Superposition of scratch data from 3 Individual scratches for a $0.5 \mathrm{M} 550^{\circ} \mathrm{C}$ sample.

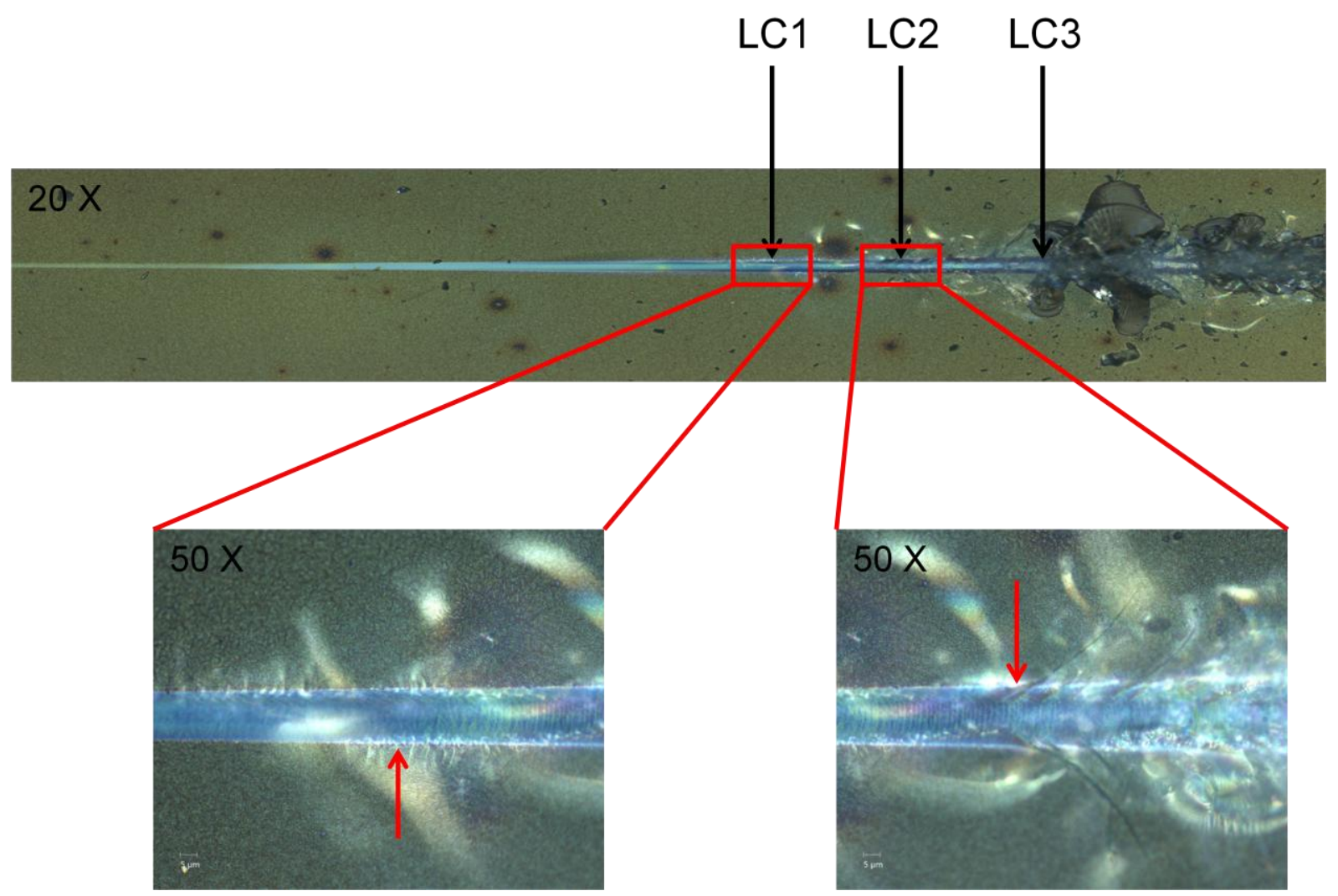

Figure 21 Optical analysis of a scratch conducted on a 0.5M 550 sample displaying critical load failures; LC1 (1.21 N), LC2 (1.43 N), and LC3 (1.68 N). 
Analysis of the results indicates that by increasing the annealing temperature above $500^{\circ} \mathrm{C}$ increases the $\mathrm{ZnO}$ coatings ability to resist the first critical failure mode $\mathrm{LC} 1$ for the $0.5 \mathrm{M}$ sample group. At an annealing temperature of $500^{\circ} \mathrm{C}, \mathrm{LC} 1$ occurs at $0.98 \pm 0.13 \mathrm{~N}$, and as the annealing temperature is increase to $550^{\circ} \mathrm{C}$ and $600^{\circ} \mathrm{C}$ the load needed to cause this first failure mechanism is increased to $1.19 \pm 0.03$ and $1.2 \pm .001$ respectively. This increase in the coatings scratch resistance as annealing temperature is increased can be attributed to the coatings increase in hardness, allowing its scratch resistance to be improved. Additionally, due to the films annealed at $500^{\circ} \mathrm{C}$ having a thinner coating, their cohesive and adhesive properties seem to have been reduced as a result of their poor film growth mechanisms. It can also be seen that there was not a significant change in the LC2 failure loads as annealing temperature was increased from $500^{\circ} \mathrm{C}$ to $600^{\circ} \mathrm{C}$, however there was seen to be an increase in the coatings ability to resist the LC3 failure at increased loads when annealed at $600^{\circ} \mathrm{C}$. Figure 22 displays panoramic images of scratches conducted on the $0.5 \mathrm{M}$ sample group at annealing temperatures of $500^{\circ} \mathrm{C}, 550^{\circ} \mathrm{C}$ and $600^{\circ} \mathrm{C}$. This figure has been included in order to provide a comparison of how increasing the annealing temperature can increase the scratch resistance of $\mathrm{ZnO}$ films. The critical failure loads of these $\mathrm{ZnO}$ films are displayed in Figure 23.

Table 7 Mean critical load values for $0.5 \mathrm{M}$ films (N)

\begin{tabular}{llll}
\hline $\mathbf{0 . 5} \mathbf{M}$ & $\mathbf{5 0 0}^{\circ} \mathbf{C}$ & $\mathbf{5 5 0}^{\mathbf{}} \mathbf{C}$ & $\mathbf{6 0 0}^{\mathbf{9}} \mathbf{C}$ \\
\hline $\mathbf{L C 1}$ & $0.98 \pm 0.13$ & $1.19 \pm 0.03$ & $1.2 \pm 0.001$ \\
$\mathbf{L C 2}$ & $1.47 \pm 0.06$ & $1.45 \pm 0.03$ & $1.53 \pm 0.06$ \\
$\mathbf{L C 3}$ & $1.61 \pm 0.10$ & $1.66 \pm 0.13$ & $1.8 \pm 0.27$ \\
\hline
\end{tabular}



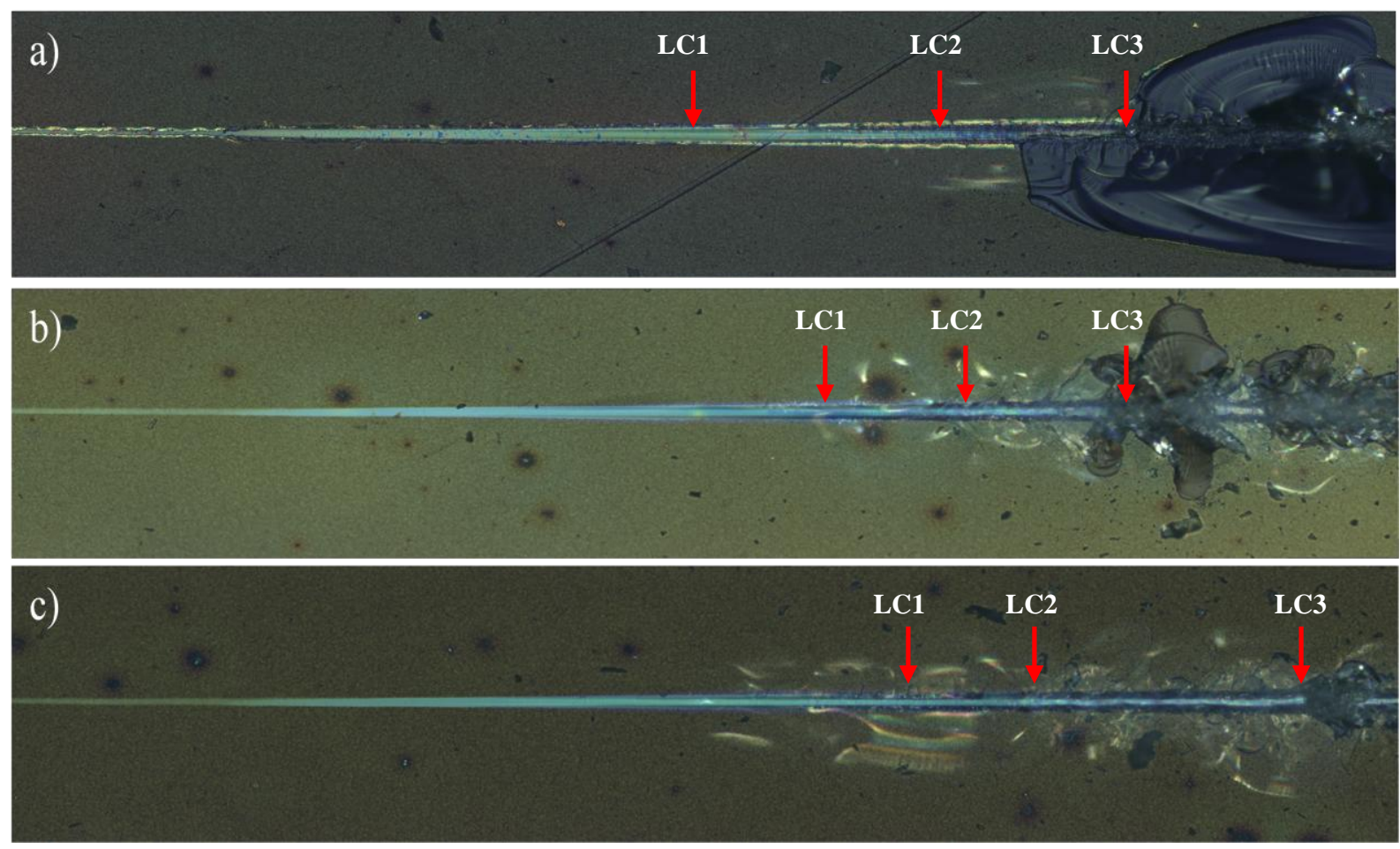

Figure 22 Panoramic images displaying the critical failure loads of scratches conducted on 0.5M sample groups at; a) $500^{\circ} \mathrm{C}$, b) $550^{\circ} \mathrm{C}$ and c) $600^{\circ} \mathrm{C}$ as the scratch progressed from left to right.

This trend was not seen for the $0.75 \mathrm{M}$ sample group however. As annealing temperature was increased, no significant increase in scratch resistance of any critical loads could be defined. This infers that there seems to be a hardness and/or thickness threshold at which the scratch resistance properties of the $\mathrm{ZnO}$ films are no longer improved. Indicating the scratch resistance of $\mathrm{ZnO}$ films is both thickness and hardness dependant.

Table 8 Mean critical load values for $0.75 \mathrm{M}$ films (N)

\begin{tabular}{lll}
\hline $\mathbf{0 . 7 5} \mathbf{M}$ & $\mathbf{5 0 0}^{\circ} \mathbf{C}$ & $\mathbf{6 0 0}^{\circ} \mathbf{C}$ \\
\hline LC1 & $1.14 \pm 0.05$ & $1.15 \pm 0.03$ \\
LC2 & $1.59 \pm 0.14$ & $1.56 \pm 0.10$ \\
LC3 & $1.77 \pm 0.09$ & $1.78 \pm 0.08$ \\
\hline
\end{tabular}




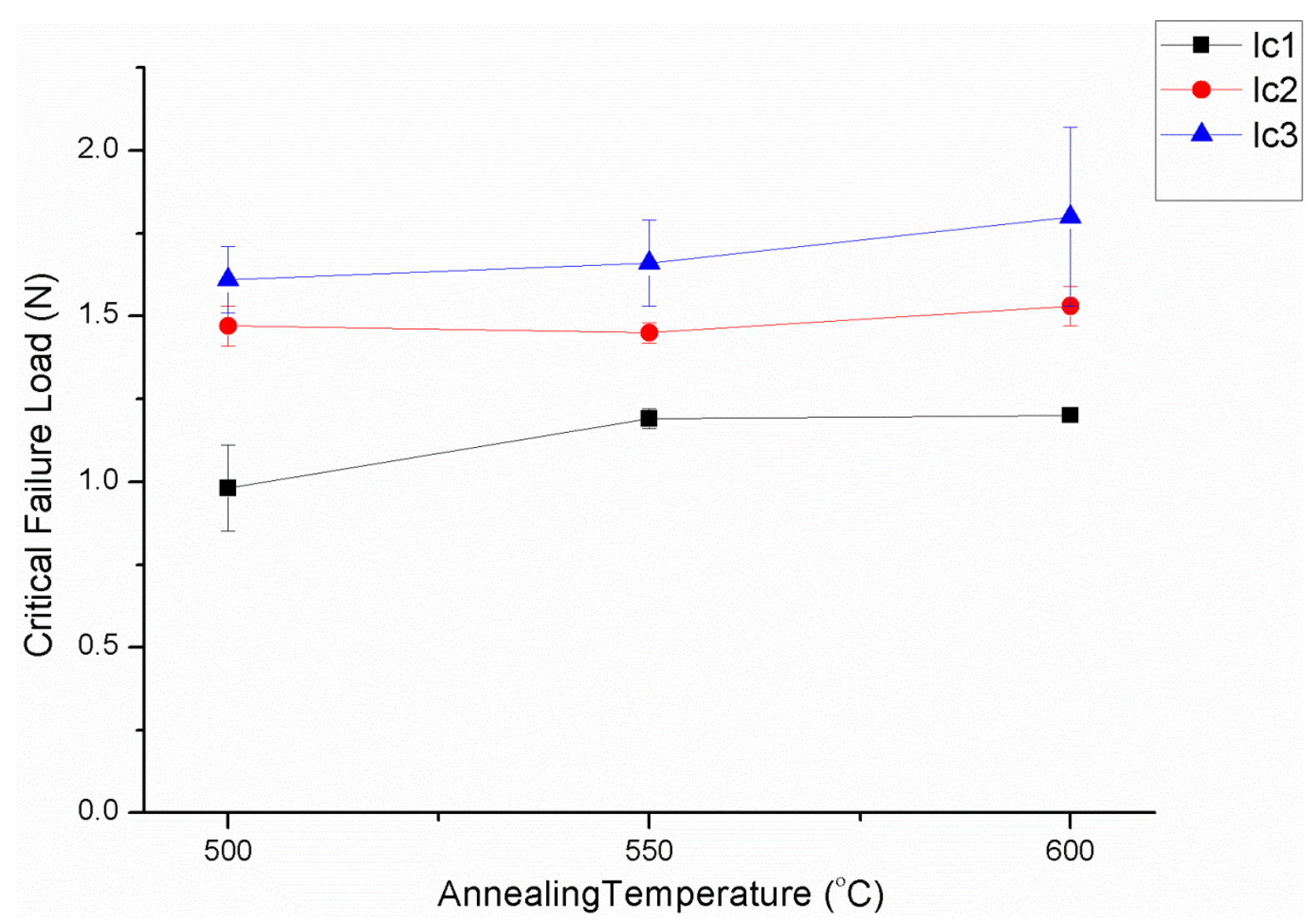

Figure 23 Mean critical failure loads of $0.5 \mathrm{M}$ sample groups at $500^{\circ} \mathrm{C}, 550^{\circ} \mathrm{C}$ and $600^{\circ} \mathrm{C}$ 


\subsubsection{Tribological properties}

In order to investigate the how annealing temperature may affect the tribological properties of $\mathrm{ZnO}$ thin films, the Anton Paar Tribometer was adopted. For this investigation, a linear reciprocating motion was adopted with a stroke length of $4 \mathrm{~mm}$. Via the instruments software, one can select a reciprocating area of interest. This allows one to focus on the dynamic frictional properties of the $\mathrm{ZnO}$ films and remove any potential error from "stick slip" at the edges of the stroke length and can be seen below in Figure 24.

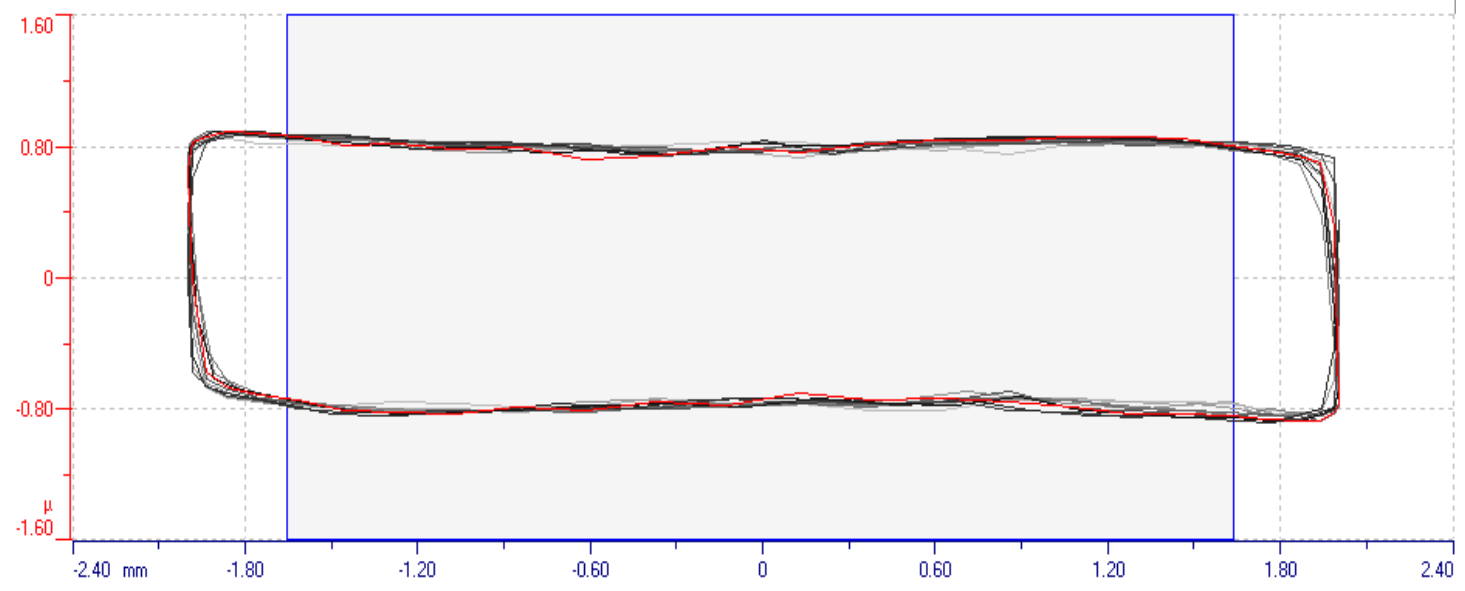

Figure 24 Area of analysis for tribological testing

From analysis of the results it can be seen that the $0.5 \mathrm{M} 500^{\circ} \mathrm{C}$ sample group exhibit the lowest coefficient of friction of $0.512 \pm 0.1$. However this is somewhat deceiving. The reasoning for this reduced mean coefficient of friction is due to the total failure of the films after $\sim 257$ wear cycles. This can be readily seen in Figure 25 where the red arrow indicates the total failure of the film. Similarly this quick initial failure was also indicated from the scratch test results, where the first critical failure load was evident for the $0.5500^{\circ} \mathrm{C}$ sample groups. Indicating that due to the poor growth mechanisms of these films caused by a lower annealing temperature, the tribological properties such as adhesion to the substrate is greatly 
reduced. For all samples tested, there was an apparent increase in the coefficient of friction as a result of sample debris build up due to the formation of adhesive junctions. Once this sample build up was overcome and brushed to the edges as debris, the coefficient of friction began to level out and became constant. The highest coefficient of friction of $0.824 \pm 0.26$ was seen within the $0.75 \mathrm{M} 500^{\circ} \mathrm{C}$ sample group.
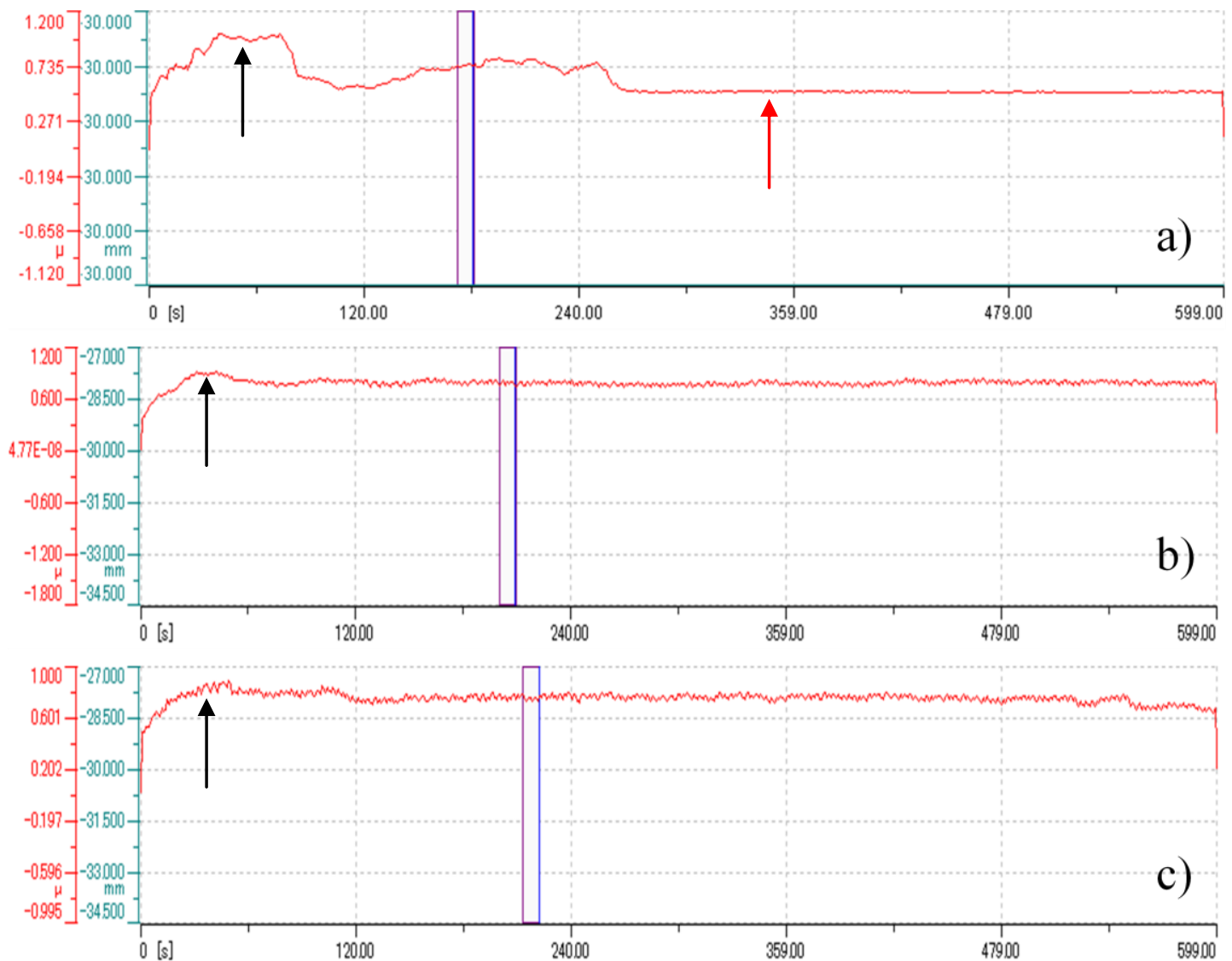

Figure 25 Linear reciprocating analysis displaying the friction coefficient of the $0.5 \mathrm{M}$ sample group annealed at; a) $\left.500^{\circ} \mathrm{C}, \mathrm{b}\right) 550^{\circ} \mathrm{C}$, and c) $600^{\circ} \mathrm{C}$. The black arrows indicate sample build up, and the red arrow indicates complete film failure.

Additionally optical microscopy was conducted upon all samples to analyse the wear tracks and to determine the wear failure mechanisms. Figure 26 shows these optical micrographs for the $0.5 \mathrm{M} 500^{\circ} \mathrm{C}$ and $600^{\circ} \mathrm{C}$ samples. Both of these micrographs display apparent abrasion 
lines along the wear track parallel to the sliding direction. Additionally, both coatings have detached material and debris typical of abrasive and surface fatigues wear mechanisms. Complete failure of the $\mathrm{ZnO}$ film can be seen, leaving the glass substrate exposed for the $0.5 \mathrm{M} 500^{\circ} \mathrm{C}$ sample group. For $0.5 \mathrm{M}$ samples annealed at $600^{\circ} \mathrm{C}$, micro-cracking perpendicular to the sliding direction can be distinguished due to cyclic stress interactions. From optical analysis, the wear resistance seems to have been increased with an increase in annealing temperature. This can be attributed to an increase in the hardness of the coating with increasing annealing temperature. These results coincide with the work conducted by (Lin and Kim, 2009).

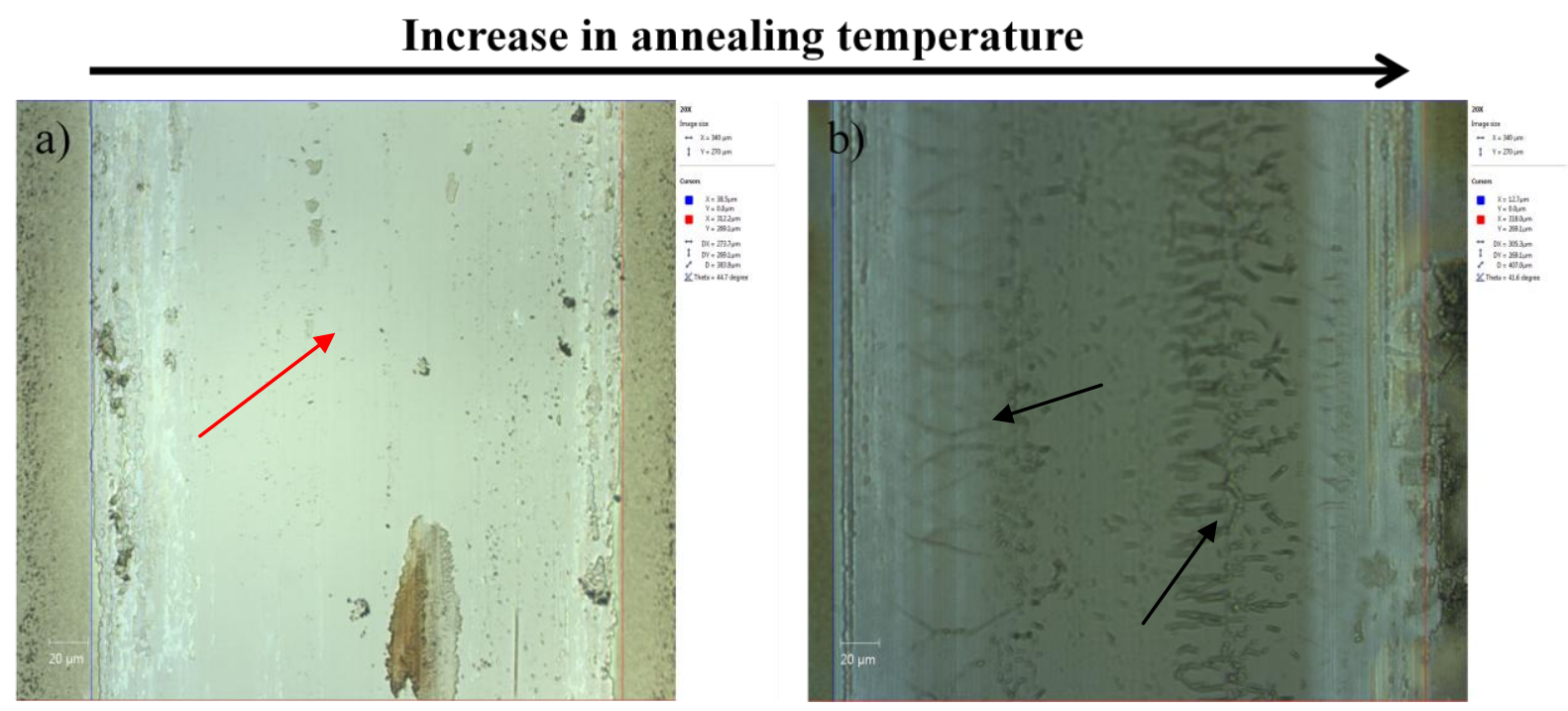

Figure 26 Optical micrographs of $0.5 \mathrm{M}$ samples wear tracks annealed at; a) $500^{\circ} \mathrm{C}$, and b) $600^{\circ} \mathrm{C}$. Red arrow $^{\circ}$ indicates exposed soda lime glass surface, black arrows indicate wear failure mechanisms.

Table 9 Mean Coefficient of Friction (CoF)

\begin{tabular}{llll}
\hline Concentration & $\mathbf{5 0 0}^{\circ} \mathbf{C}$ & $\mathbf{5 5 0}^{\circ} \mathbf{C}$ & $\mathbf{6 0 0}^{\circ} \mathbf{C}$ \\
\hline $\mathbf{0 . 5} \mathbf{M}$ & $0.512 \pm 0.1$ & $0.796 \pm 0.09$ & $0.765 \pm 0.11$ \\
$\mathbf{0 . 7 5} \mathbf{M}$ & $0.824 \pm 0.26$ & N/A & $0.707 \pm 0.09$ \\
& & & \\
\hline
\end{tabular}




\subsection{Surface analysis}

\subsection{1 $\mathrm{ZnO}$ surface investigation}

SEM analysis was conducted on all $\mathrm{ZnO}$ films in order to analyse how a change in annealing temperature may influence the microstructure and growth mechanisms of these films. During analysis a clean region was selected for observation. It can be seen from Figure 27 Figure 28 that increasing both the zinc concentration and annealing temperature, results in an increase of grain size and density. From these micrographs, Image $\mathbf{J}$ analysis was used in order to measure the grain size of these $\mathrm{ZnO}$ films. The results can be found below in Table 10 which indicates that the grain size increases as the annealing temperature increases, indicating the grain size of $\mathrm{ZnO}$ films is directly affected by the annealing temperature. This is due to an increase of the atom mobility and crystallite cross linking to form larger grains. Furthermore, the decrease in optical transmission previously discussed in section 4.1.2 can be related to the large grain size for all samples and the high standard deviation. This SEM analysis confirms the previous findings from XRD analysis is section 4.1.1, and agrees with previous work by Shinde et al., (2007) and Lin and Kim (2009).

Table 10 Summery of mean $\mathrm{ZnO}$ grain sixe $(\mathrm{nm})$ from $500^{\circ} \mathrm{C}$ to $600^{\circ} \mathrm{C}$

\begin{tabular}{lccc}
\hline Concentration & $\mathbf{5 0 0}^{\mathbf{}} \mathbf{C}$ & $\mathbf{5 5 0}^{\mathbf{C}} \mathbf{C}$ & $\mathbf{6 0 0}^{\circ} \mathbf{C}$ \\
\hline $\mathbf{0 . 5} \mathbf{M}$ & $55 \pm 6$ & $66 \pm 5$ & $73 \pm 14$ \\
$\mathbf{0 . 7 5} \mathbf{M}$ & $66 \pm 11$ & N/A & $81 \pm 12$ \\
& & & \\
\hline
\end{tabular}




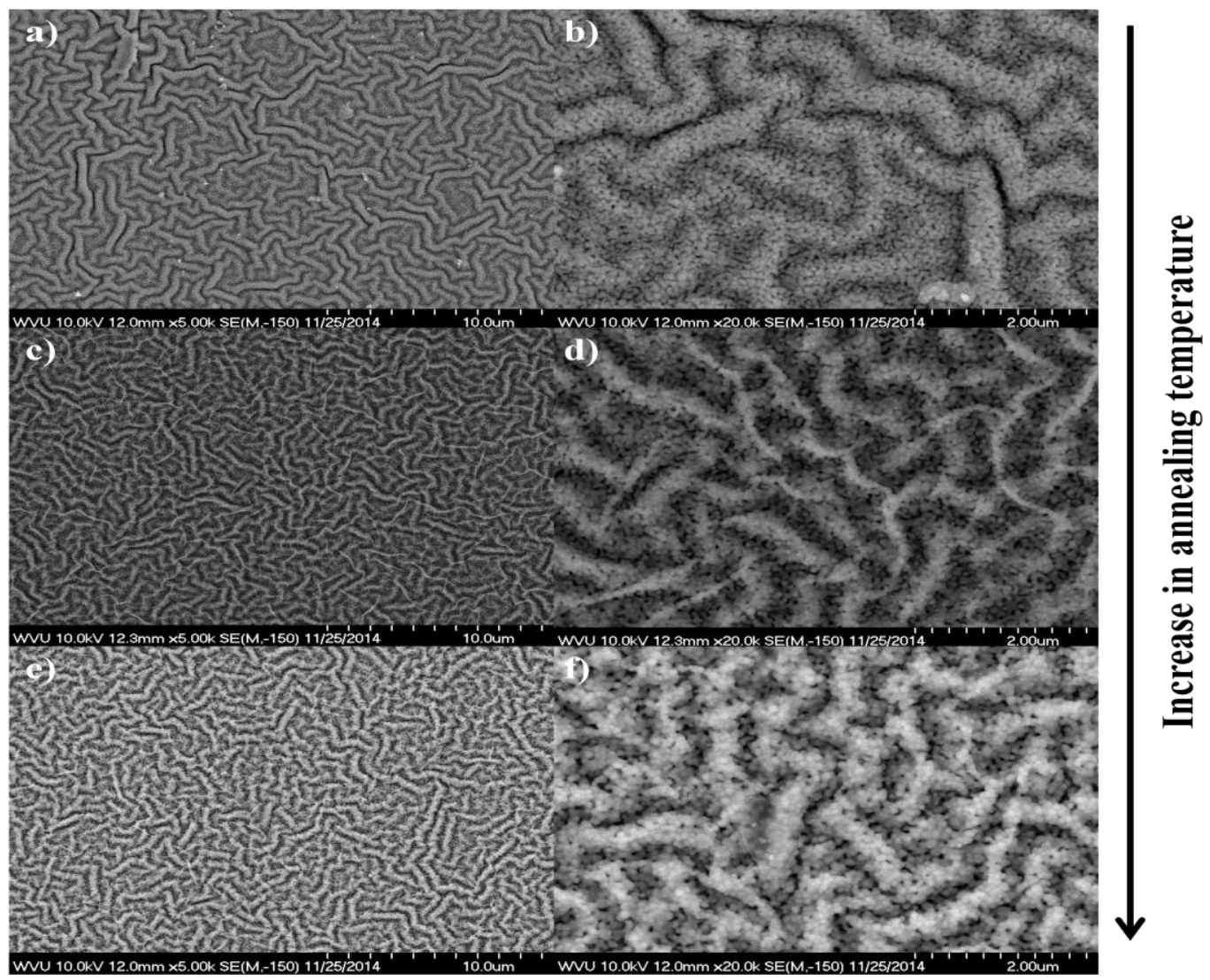

Figure $27 \mathrm{SEM}$ micrographs of $0.5 \mathrm{M}$ samples annealed at; a) and b) $500^{\circ} \mathrm{C}$, c) and d) $550^{\circ} \mathrm{C}$, e) and f) $600^{\circ} \mathrm{C}$.

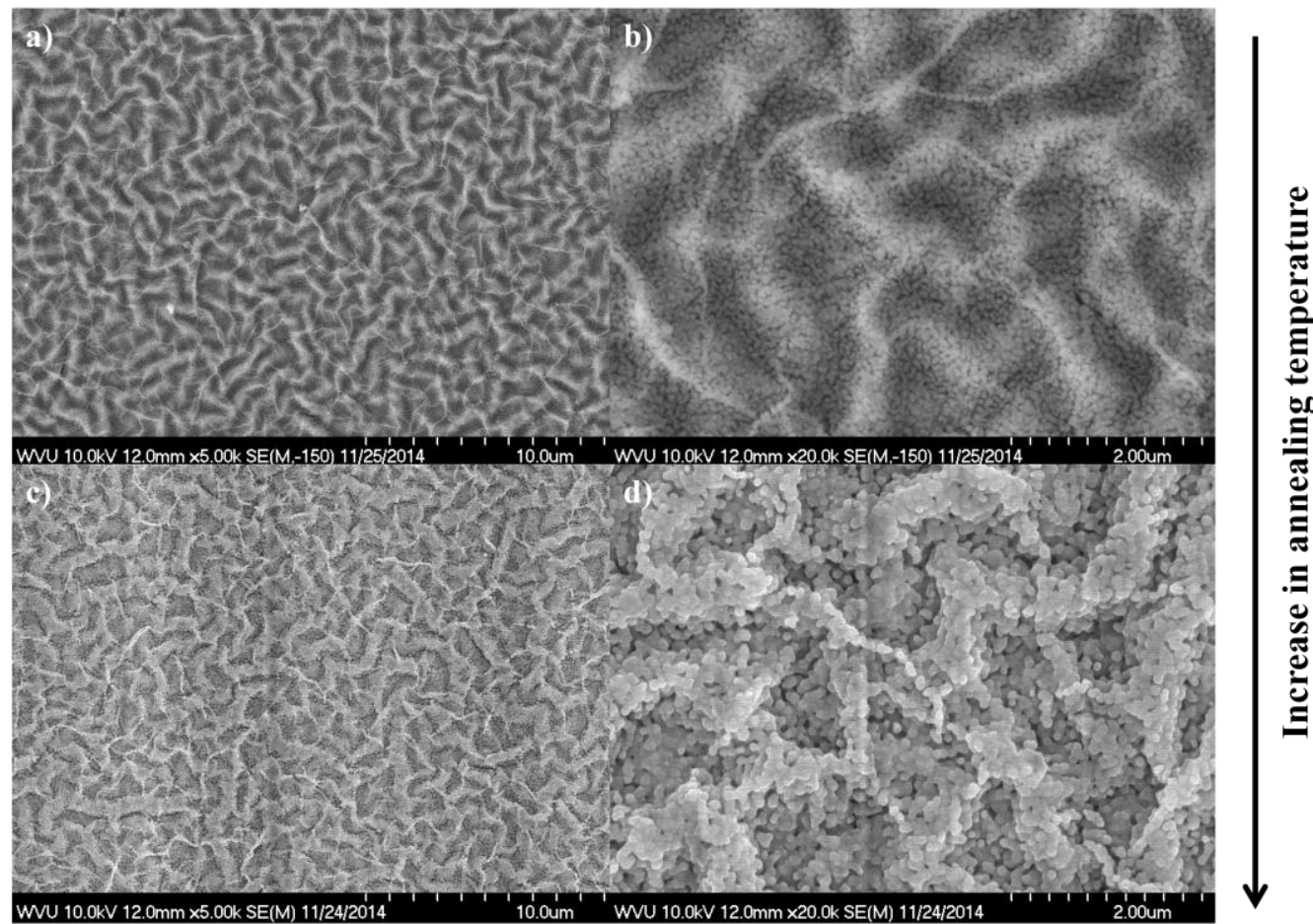

Figure $28 \mathrm{SEM}$ micrographs of $0.75 \mathrm{M}$ samples annealed at; a) and b) $500^{\circ} \mathrm{C}$, c) and d) $600^{\circ} \mathrm{C}$ 


\subsubsection{Ex-situ SEM investigation after mechanical characterization}

Further surface analysis of all $\mathrm{ZnO}$ films after scratch testing were investigated using the $e x$ situ SEM technique in order to observe the films failure mechanisms to a greater degree. The following micrographs display samples that were subjected to a $1 \mathrm{~mm}$ scratch length with a linearly increasing load of 0.3 to $2 \mathrm{~N}$ using a $20 \mu \mathrm{m}$ sphero-conical tip.

As previously discussed in section 4.2 .2 , as the normal load is linearly increased differing failure mechanisms can occur and become more pronounced as the normal load is further increased. Figure 29 displays SEM micrographs of the $\mathrm{ZnO}$ film previously shown in Figure 21 and its failure mechanisms; where the first critical failure load, LC1 (1.21 N) is shown in micrograph b), and the second critical failure load, LC2 $(1.43 \mathrm{~N})$ is displayed in micrograph a) as the scratch progressed from right to left. Here the cohesive failure of the $\mathrm{ZnO}$ films via tensile micro-cracking can be seen more clearly, and is notated by a black arrow in micrograph b). As the normal load is increased further, we can see the onset of tunnelling crack formation at these tensile micro-cracks in the middle of the scratch, which propagate towards the edge of the scratch and cause the onset of film delamination. These phenomena can be seen in micrograph a) and the onset of the tunnelling crack formation is notated by the red arrows.

Furthermore, ex-situ SEM provided further insight into the $\mathrm{ZnO}$ films failure mechanisms which could not easily be seen via optical microscopy. Figure 30 displays a comparison between two $\mathrm{ZnO}$ films annealed at $500^{\circ} \mathrm{C}$ and $600^{\circ} \mathrm{C}$. Here it can be seen that when the $\mathrm{ZnO}$ film was annealed at $500^{\circ} \mathrm{C}$, delamination occurred at the edges of the scratch without being induced by the tunnelling crack formation, indicating poor adhesion to the glass substrate. This was not seen when the $\mathrm{ZnO}$ film was annealed at $600^{\circ} \mathrm{C}$ however, where only a small degree of cohesive failure can be seen at the edge of the scratch. These results support 
the notion that film adhesion and scratch resistance is improved as annealing temperature is increased.
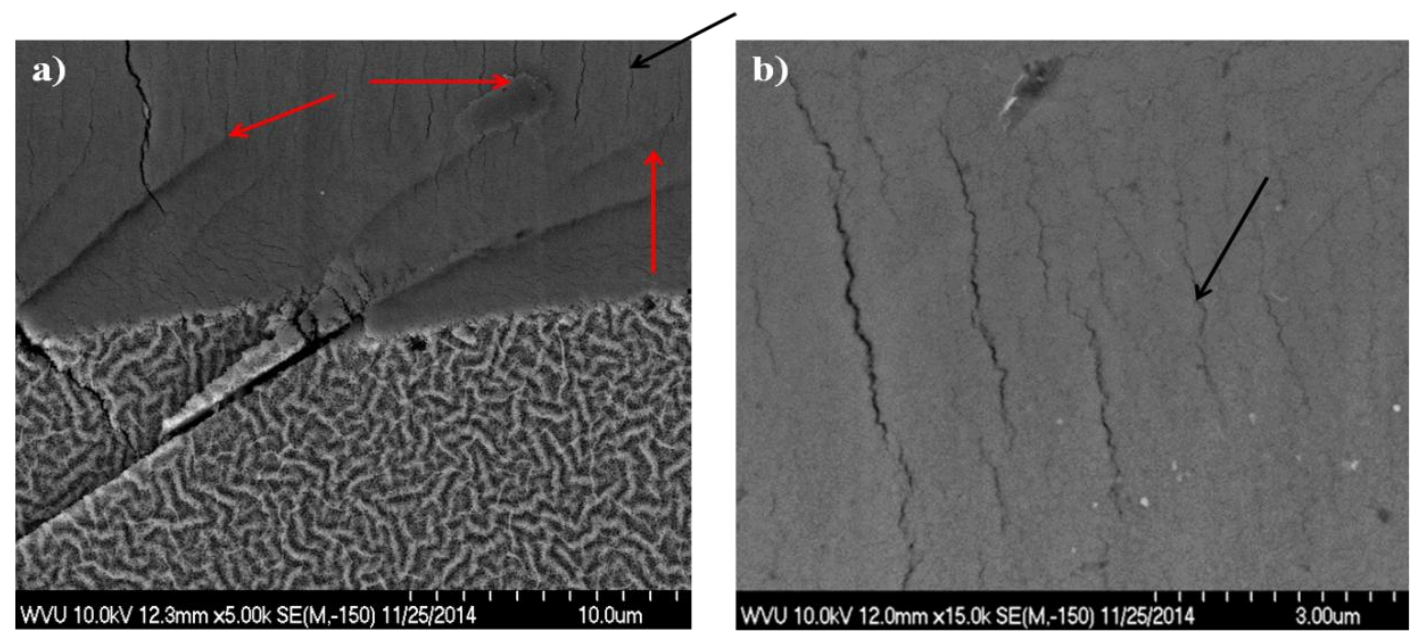

Figure 29 Ex-situ SEM micrographs of 0.5 M ZnO film annealed at $550^{\circ} \mathrm{C}$ displaying critical failure loads; a) Lc2, b) Lc1 as the scratch progresses from right to left. Black arrows indicate cohesive tensile micro-cracking and red arrows indicate onset of tunnelling crack formation leading to delamination.

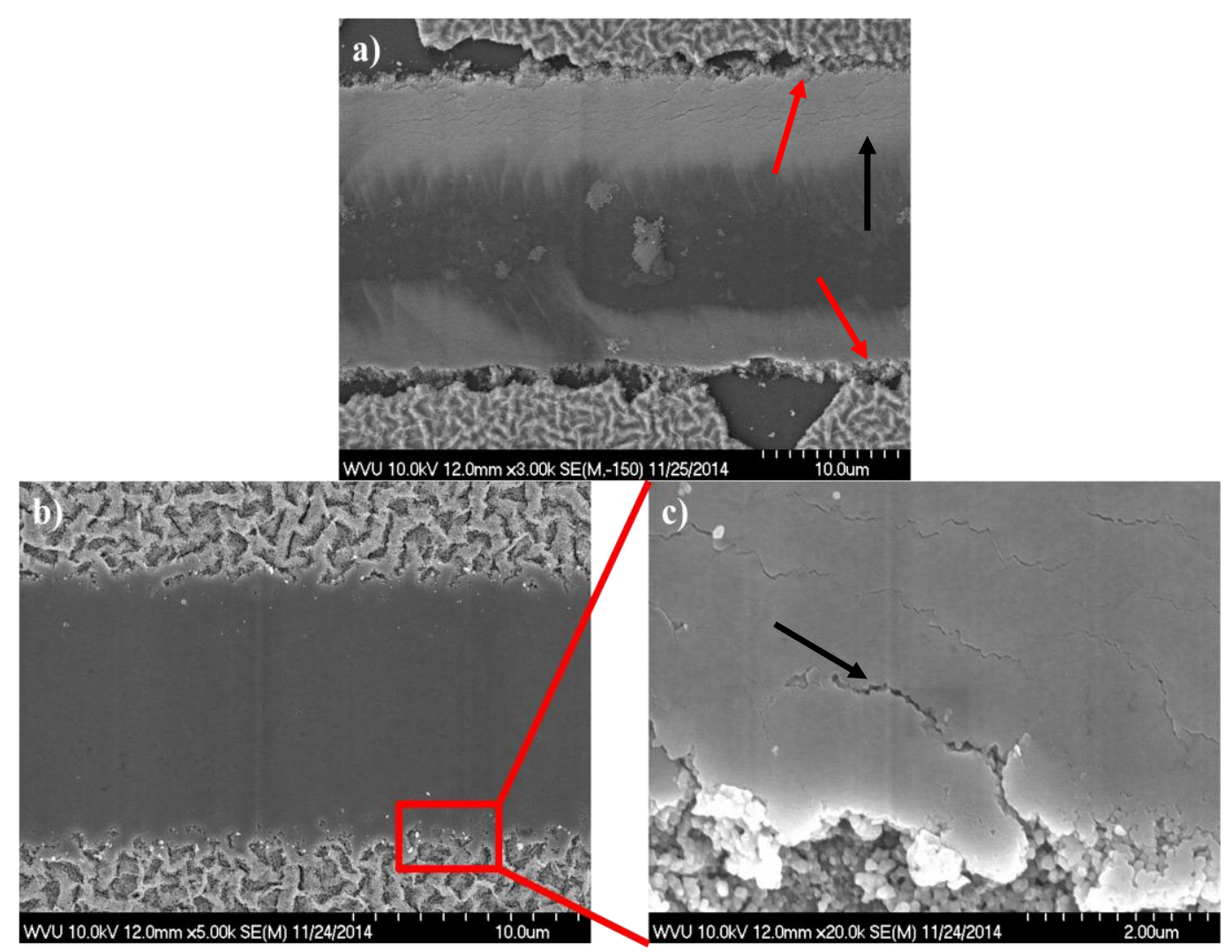

Figure $30 \mathrm{Ex}$-situ SEM micrographs of $0.75 \mathrm{M} \mathrm{ZnO} \mathrm{films} \mathrm{annealed} \mathrm{at;} 500^{\circ} \mathrm{C}$ (a) and $600{ }^{\circ} \mathrm{C}(\mathrm{b})$ and (c). Black arrows indicate cohesive tensile micro-cracking and red arrows indicate film delamination. 


\section{Conclusions}

Through the work of this study; the optical, structural, mechanical and tribological properties of sol-gel $\mathrm{ZnO}$ films have been thoroughly investigated. It can be seen that whilst sol-gel $\mathrm{ZnO}$ films offer many advantageous features, enabling them to be viable candidates as an alternative to ITO as a transparent conducting oxide in a range of applications such as solar cells and sensing devices, great care and understanding of the $\mathrm{ZnO}$ films properties must be taken into account during the design and fabrication phase in order to maximise their efficiency in service. From the work conducted in this study the following conclusions can be made;

- All sol-gel $\mathrm{ZnO}$ films fabricated via the dip coating method displayed well ordered, polycrystalline films with a hexagonal wurtzite structure. The crystallinity of these $\mathrm{ZnO}$ films can be seen to increase as both the sol concentration and annealing temperature is increased. This can be attributed to an increase in the $\mathrm{Zn}^{2+}$ species available to facilitate well ordered $\mathrm{ZnO}$ film growth as the initial zinc concentration of the sol is increased, and the increase in annealing temperature enhances $\mathrm{ZnO}$ film crystallinity whilst increasing grain size.

- Increasing the sol concentration will result in the sol-gel $\mathrm{ZnO}$ films thickness to increase. In this study it was seen that increasing the sol concentration from $0.5 \mathrm{M}$ to $0.75 \mathrm{M}$ would cause an increase in film thickness from $0.67 \pm 0.12$ to $0.89 \pm 0.07 \mu \mathrm{m}$ when annealed at $600^{\circ} \mathrm{C}$ for 1 hour.

- Furthermore, increasing the annealing temperature also resulted in an increase of the $\mathrm{ZnO}$ film thickness. As the annealing temperature was increased from $500^{\circ} \mathrm{C}$ to $600^{\circ} \mathrm{C}, \mathrm{ZnO}$ films fabricated at a sol concentration of $0.5 \mathrm{M}$ increased from $0.57 \pm 0.07$ to $0.67 \pm 0.12 \mu \mathrm{m}$. 
- However, increasing the annealing temperature from $500^{\circ} \mathrm{C}$ to $550^{\circ} \mathrm{C}$ was not observed to affect the resultant $\mathrm{ZnO}$ film's thickness values. Inferring that an optimal annealing temperature which facilitates an increase in grain growth lies between $550^{\circ} \mathrm{C}$ to $600^{\circ} \mathrm{C}$.

- Both sol concentration and annealing temperature heavily influence the optical properties of $\mathrm{ZnO}$ films. It was seen that increasing the sol concentration and the annealing temperature caused a decrease in the $\mathrm{ZnO}$ films optical transmission. As the sol-concentration was kept constant at $0.5 \mathrm{M}$, and annealing temperature was increased, the optical transmission could be seen to decrease from $73 \%$ to $66 \%$. Increasing the sol concentration further facilitated the deterioration in optical transmission as $\mathrm{ZnO}$ films fabricated from a $0.75 \mathrm{M}$ sol and annealed at $600^{\circ} \mathrm{C}$ for 1 hour, displayed an average optical transmission of just $44 \%$ in the visible wavelength spectrum.

- Hardness and Young's Modulus of sol-gel ZnO films can be improved via an increase in annealing temperature. Nanoindentation showed an increase in both hardness and elastic moduli as the annealing temperature was increased. Increasing the annealing temperature of from $500^{\circ} \mathrm{c}$ to $600^{\circ} \mathrm{C}$ increased the films mean hardness from $1.79 \pm 0.57$ to $2.68 \pm 0.87$ whilst sol-concentration was kept constant. The Young's Modulus of the $\mathrm{ZnO}$ films were also seen to increase, with values of $70.19 \pm 17.89$, $72.34 \pm 12.04,73.72 \pm 11.84$ after a 1 hour annealing time at $500^{\circ} \mathrm{C}, 550^{\circ} \mathrm{C}$ and $600^{\circ} \mathrm{C}$ respectively. These phenomena are attributed to an increase in crystallinity as a result of increasing annealing temperature.

- The scratch resistance of $\mathrm{ZnO}$ films can be improved by an increase in annealing temperature. The increase in hardness, Young's Modulus, and crystallinity of $\mathrm{ZnO}$ 
films as annealing temperature is increased, contributes to an enhancement of cohesive properties and adhesion of the film to the substrate material. Further increasing the $\mathrm{ZnO}$ films ability to resist critical failure loads.

- Micro-cracking, delamination and chipping can be identified as critical load failure mechanisms via ex-situ microscopy.

- Tribological analysis indicated the wear resistance of sol-gel $\mathrm{ZnO}$ films could also be improved via an increase in annealing temperature. This is due to the enhancement of crystallinity, hardness, and adhesive properties which are promoted at elevated annealing temperatures. Micro-crack failure mechanisms were observed perpendicular to the wear direction.

- Overall, the mechanical properties of sol-gel $\mathrm{ZnO}$ films are improved as a result of increasing annealing temperature.

To conclude; the influence of annealing temperature can play a major role in determining the mechanical properties of sol-gel $\mathrm{ZnO}$ films. Whilst increasing the annealing temperature can be seen to improve the mechanical properties of such films, the optical properties are also heavily affected. With this in hand, it is imperative that annealing temperatures are controlled in order to yield sol-gel coated films with enhanced mechanical, tribological, and optical properties. 


\section{Future Work}

As a result of this study, we have observed that control of the annealing temperature during $\mathrm{ZnO}$ film fabrication is of the upmost importance. Furthermore, we have gained a broader understanding into the growth mechanisms, optical changes and mechanical reliability of $\mathrm{ZnO}$ films. With this in mind, this work paves way for future investigations.

Dopant materials of differing weight percentages such as Aluminium could be added to gain an indication of how the addition of impurities may improve or reduce the mechanical properties of such films compared to the findings within this study.

Additionally, numerous applications that utilize TCO coatings often require multiple components to be stacked on top of one another. During this stacking process, components are glued together using a epoxy resins in order to manufacture the final product. These epoxy resins often include numerous acids such as acrylic acid within their active ingredients, which could corrode and facilitate failure. Wear and scratch test investigations before, during, and after acidic exposure could provide insight onto how acidic environments affect the reliability of such films.

Finally, since the electronic properties of $\mathrm{ZnO}$ films were not a focal point of this study, one could look into analyzing the infrared absorption of such films in order to measure their charge carrier concentration. 


\section{References}

BANERJEE, D. 2012. Sol-Gel Derived Wear-Resistant, Hydrophobic, Particle-Reinforced Silica Coatings. Mechanical Enngineering Masters, West Virginia University.

BRINKER, C. J. \& SCHERER, G. W. 1990. Sol-gel science: the physics and chemistry of sol-gel processing, Gulf Professional Publishing.

CHENG, Y.-T., HO, J.-J., WANG, C.-K., LEE, W., LU, C.-C., YAU, B.-S., NAIN, J.-L., CHANG, S.-H., CHANG, C.-C. \& WANG, K. L. 2010. Improvement of organic solar cells by flexible substrate and ITO surface treatments. Applied Surface Science, 256, 7606-7611.

CHOI, M.-C., KIM, Y. \& HA, C.-S. 2008. Polymers for flexible displays: From material selection to device applications. Progress in Polymer Science, 33, 581-630.

CHUNG, W., THOMPSON, M. O., WICKBOLDT, P., TOET, D. \& CAREY, P. G. 2004. Room temperature indium tin oxide by $\mathrm{XeCl}$ excimer laser annealing for flexible display. Thin Solid Films, 460, 291-294.

ELLMER, K. 2001. Resistivity of polycrystalline zinc oxide films: current status and physical limit. Journal of Physics D: Applied Physics, 34, 3097.

GONG, H., HU, J. Q., WANG, J. H., ONG, C. H. \& ZHU, F. R. 2006. Nano-crystalline Cudoped ZnO thin film gas sensor for CO. Sensors and Actuators B: Chemical, 115, 247-251.

HAMROUNI, A., MOUSSA, N., PARRINO, F., DI PAOLA, A., HOUAS, A. \& PALMISANO, L. 2014. Sol-gel synthesis and photocatalytic activity of ZnO-SnO2 nanocomposites. Journal of Molecular Catalysis A: Chemical, 390, 133-141.

HARTNAGEL, H. 1995. Semiconducting Transparent Thin Films, Taylor \& Francis. 
KIM, H. 2007 Transparent Conducting Oxide Films Pulsed Laser Deposition of Thin Films: Applications-Led Growth of Functional Materials. Hoboken, New Jersey Wiley \& Sons, inc. .

KIM, H., GILMORE, C. M., HORWITZ, J. S., PIQUÉ, A., MURATA, H., KUSHTO, G. P., SCHLAF, R., KAFAFI, Z. H. \& CHRISEY, D. B. 2000. Transparent conducting aluminum-doped zinc oxide thin films for organic light-emitting devices. Applied Physics Letters, 76, 259-261.

KIM, H., HORWITZ, J. S., KUSHTO, G. P., KAFAFI, Z. H. \& CHRISEY, D. B. 2001. Indium tin oxide thin films grown on flexible plastic substrates by pulsed-laser deposition for organic light-emitting diodes. Applied Physics Letters, 79, 284-286.

KIRIAKIDIS, G., KORTIDIS, I., CRONIN, S. D., MORRIS, N. J., CAIRNS, D. R. \& SIERROS, K. A. 2014. Tribological investigation of piezoelectric $\mathrm{ZnO}$ films for rolling contact-based energy harvesting and sensing applications. Thin Solid Films, $555,68-75$.

KO, Y. H., KIM, M. S. \& YU, J. S. 2012. Controllable electrochemical synthesis of ZnO nanorod arrays on flexible ITO/PET substrate and their structural and optical properties. Applied Surface Science, 259, 99-104.

KUMAR, A., HUANG, N., STAEDLER, T., SUN, C. \& JIANG, X. 2013. Mechanical characterization of aluminum doped zinc oxide $(\mathrm{Al}: \mathrm{ZnO})$ nanorods prepared by solgel method. Applied Surface Science, 265, 758-763.

LENNON, C., TAPIA, R. B., KODAMA, R., CHANG, Y., SIVANANTHAN, S. \& DESHPANDE, M. 2009. Effects of Annealing in a Partially Reducing Atmosphere on Sputtered Al-Doped ZnO Thin Films. Journal of Electronic Materials, 38, 1568-1573. 
LI, J., XU, J., XU, Q. \& FANG, G. 2012. Preparation and characterization of Al doped ZnO thin films by sol-gel process. Journal of Alloys and Compounds, 542, 151-156.

LIN, L.-Y. \& KIM, D.-E. 2009. Effect of annealing temperature on the tribological behavior of $\mathrm{ZnO}$ films prepared by sol-gel method. Thin Solid Films, 517, 1690-1700.

LIU, X., PAN, K., LI, W., HU, D., LIU, S. \& WANG, Y. 2014. Optical and gas sensing properties of $\mathrm{Al}$-doped $\mathrm{ZnO}$ transparent conducting films prepared by sol-gel method under different heat treatments. Ceramics International, 40, 9931-9939.

MALEK, M. F., MAMAT, M. H., KHUSAIMI, Z., SAHDAN, M. Z., MUSA, M. Z., ZAINUN, A. R., SURIANI, A. B., MD SIN, N. D., ABD HAMID, S. B. \& RUSOP, M. 2014. Sonicated sol-gel preparation of nanoparticulate $\mathrm{ZnO}$ thin films with various deposition speeds: The highly preferred c-axis $(0 \& \# x a 0 ; 0 \& \# x a 0 ; 2)$ orientation enhances the final properties. Journal of Alloys and Compounds, 582, 12-21.

MICCOLI, I., SPAMPINATO, R., MARZO, F., PRETE, P. \& LOVERGINE, N. 2014. DCmagnetron sputtering of $\mathrm{ZnO}: \mathrm{Al}$ films on (00.1)Al2O3 substrates from slip-casting sintered ceramic targets. Applied Surface Science, 313, 418-423.

MIKHAIL F. LIMONOV, R. M. D. L. R. 2012. Optical Properties of Photonic Structures: Interplay of Order and Disorder, Forida, USA., CRC Press.

MINAMI, T. 2005. Transparent conducting oxide semiconductors for transparent electrodes. Semiconductor Science and Technology, 20, S35.

OLIVER, W. C. \& PHARR, G. M. 1992. An improved technique for determining hardness and elastic modulus using load and displacement sensing indentation experiments. Journal of Materials Research, 7, 1564-1583. 
PADMAVATHY, N. \& VIJAYARAGHAVAN, R. 2008. Enhanced bioactivity of ZnO nanoparticles_-an antimicrobial study. Science and Technology of Advanced Materials, 9, 035004.

PARAGUAY D, F., ESTRADA L, W., ACOSTA N, D. R., ANDRADE, E. \& MIKIYOSHIDA, M. 1999. Growth, structure and optical characterization of high quality ZnO thin films obtained by spray pyrolysis. Thin Solid Films, 350, 192-202.

PIERRE, A. C. 1998. Introduction to Sol-Gel Processing, Springer US.

RAJESHWAR, K., OSUGI, M. E., CHANMANEE, W., CHENTHAMARAKSHAN, C. R., ZANONI, M. V. B., KAJITVICHYANUKUL, P. \& KRISHNAN-AYER, R. 2008. Heterogeneous photocatalytic treatment of organic dyes in air and aqueous media. Journal of Photochemistry and Photobiology C: Photochemistry Reviews, 9, 171-192.

SCHUBERT, S., MÜLLER-MESKAMP, L. \& LEO, K. 2014. Unusually High Optical Transmission in Ca:Ag Blend Films: High-Performance Top Electrodes for Efficient Organic Solar Cells. Advanced Functional Materials, 24, 6668-6676.

SHINDE, V. R., GUJAR, T. P. \& LOKHANDE, C. D. 2007. LPG sensing properties of ZnO films prepared by spray pyrolysis method: Effect of molarity of precursor solution. Sensors and Actuators B: Chemical, 120, 551-559.

SIERROS, K. A., BANERJEE, D. A., MORRIS, N. J., CAIRNS, D. R., KORTIDIS, I. \& KIRIAKIDIS, G. 2010. Mechanical properties of $\mathrm{ZnO}$ thin films deposited on polyester substrates used in flexible device applications. Thin Solid Films, 519, 325330.

SIERROS, K. A., BEJITUAL, T. S., CRONIN, S., KESSMAN, A. J., KUKUREKA, S. N. \& CAIRNS, D. R. 2011. Tribo-corrosion of Ag and Ag-alloy ITO multilayers used in solar energy applications. Wear, 271, 1438-1444. 
SWAPP, S. 2013. Scanning Electron Microscope (SEM) [Online]. Available: http://serc.carleton.edu/research_education/geochemsheets/techniques/SEM.html [Accessed 01/12/2013 2013].

THANGARAJU, B. \& KALIANNAN, P. 2000. Spray pyrolytic deposition and characterization of SnS and SnS 2 thin films. Journal of Physics D: Applied Physics, 33,1054

THONGSURIWONG, K., AMORNPITOKSUK, P. \& SUWANBOON, S. 2013. Structure, morphology, photocatalytic and antibacterial activities of $\mathrm{ZnO}$ thin films prepared by sol-gel dip-coating method. Advanced Powder Technology, 24, 275-280.

WANG L., Z. X., ZHAO S., ZHOU G., ZHOU Y., QI J. 2005 Synthesis of well-aligned ZnO nanowires by simple physical vapor deposition on c-oriented $\mathrm{ZnO}$ thin films without catalysts or additives. Applied Physics Letters 86.

YOON, D. H. \& CHOI, G. M. 1997. Microstructure and CO gas sensing properties of porous $\mathrm{ZnO}$ produced by starch addition. Sensors and Actuators B: Chemical, 45, 251-257.

YOUNG-SOON KIM, Y.-C. P., S.G. ANSARI, JEONG-YOUNG LEE, BYUNG-SOO LEE, \& SHIN, H.-S. 2003. Influence of O2 admixture and sputtering pressure on the properties of ITO thin films deposited on PET substrate using RF reactive magnetron sputtering. Surface and Coatings Technology, 229-308.

ZNAIDI, L. 2010. Sol-gel-deposited ZnO thin films: A review. Materials Science and Engineering: B, 174, 18-30.

ZNAIDI, L., SOLER ILlIA, G. J. A. A., BENYAHIA, S., SANCHEZ, C. \& KANAEV, A. V. 2003. Oriented $\mathrm{ZnO}$ thin films synthesis by sol-gel process for laser application. Thin Solid Films, 428, 257-262. 